\title{
EDUCACIÓN EN TIEMPOS DE PANDEMIA: ANTECEDENTES Y RECOMENDACIONES PARA LA DISCUSIÓN EN CHILE
}

\author{
Sylvia Eyzaguirre \\ Centro de Estudios Públicos, Chile \\ Carmen Le Foulon \\ Centro de Estudios Públicos, Chile \\ Valentina Salvatierra \\ Centro de Estudios Públicos, Chile
}

Sylvia Eyzaguirre es Doctora en Filosofía, Universidad Albert-Ludwig, Freiburg, Alemania. Investigadora del Centro de Estudios Públicos, Chile. Dirección: Monseñor Sótero Sanz 162, Providencia, Santiago, Chile, CP 7500011. Email: seyzaguirre@cepchile.cl

Carmen Le Foulon es Doctora en Ciencia Política, Universidad de Columbia, EEUU. Coordinadora del Programa de Opinión Pública del Centro de Estudios Públicos, Chile. Integrante de la Red de Politólogas. Dirección: Monseñor Sótero Sanz 162, Providencia, Santiago, Chile, CP 7500011. Email: clefoulon@cepchile.cl.

Valentina Salvatierra es Magíster en Sociología, Universidad de Oxford, Reino Unido. Investigadora asistente del Centro de Estudios Públicos, Chile, en el área de opinión pública. Dirección: Monseñor Sótero Sanz 162, Providencia, Santiago, Chile, CP 7500011. Email: vsalvatierra@cepchile.cl.

Las autoras agradecen las sugerencias y comentarios de Aldo Mascareño, Mauricio Villena, Luz María Budge, Adolfo Fuentes, Clemente Larraín y Carolina Velasco. 
RESUMEN: ¿Cuáles son los costos de mantener cerrados los establecimientos escolares hasta 2021?; esta es la pregunta que motiva este artículo. En el último tiempo hemos presenciado el llamado de parte de autoridades a retrasar el retorno a clases presenciales hasta el próximo año. Sin embargo, dicho llamado parece ignorar los efectos adversos que tiene esta medida en la población infanto-juvenil de Chile, que afecta a más de 3,5 millones de niños y jóvenes. El presente artículo busca visibilizar los posibles efectos adversos de la prolongada suspensión de clases sobre los aprendizajes de los estudiantes y los riesgos derivados de ello, como el aumento de las brechas de aprendizaje y de la deserción escolar. Para ello, analizamos tres factores que la literatura considera clave en el aprendizaje a distancia: habilidades críticas para el aprendizaje a distancia, condiciones materiales de la vivienda y apoyo de la familia. A partir de la información disponible (CASEN 2017; SIMCE 2017, 2018, entre otros), encontramos que uno de cada cinco escolares presenta carencias importantes en las dimensiones analizadas. Sin embargo, mientras casi un tercio de los estudiantes del primer quintil de ingresos se encuentra en el grupo de mayor riesgo, solo el 6\% de los escolares del quintil más rico se encuentra dentro de este grupo. La suspensión prolongada de clases presenciales afecta de forma más pronunciada a los niños y jóvenes más vulnerables del país, y puede tener efectos adversos de largo plazo si aumenta la deserción escolar y las brechas de aprendizaje.

PALABRAS ClAVE: COVID-19, sistema escolar, aprendizaje a distancia, brechas de aprendizaje, rezago en los aprendizajes, deserción escolar

RECIBIDO: mayo 2020 / ACEPTADO: agosto 2020

\section{EDUCATION IN TIMES OF PANDEMIC: BACKGROUND AND RECOMMENDATIONS FOR DISCUSSION IN CHILE}

ABSTRACT: What are the costs of keeping schools closed until 2021?; this is the main question behind this article. Several public authorities have called to delay the return to in-person classroom until next year. However, this call seems to ignore the adverse effects this measure has on Chilean young population, which comprises more than 3.5 million children and youth. This article aims to make visible the potential negative effects of extended school closure on student's learning and development opportunities, and the risks derived from these, such as wider education gaps and greater school dropout rates. To this end, we analyze three key factors for distance learning according to the literature: critical skills for distance learning, housing conditions, and parental support. Using the available data (CASEN 2017; SIMCE 2017, 2018, among others), we find that one in five schoolchildren has significant deficiencies in the analyzed dimen- 
sions. Whereas nearly a third of the schoolchildren in the lowest income quintile are in the highest risk group, only $6 \%$ of schoolchildren in the highest income quintile are in this group. Extended school closure carries high costs for children and youth, particularly for the most vulnerable. These costs may be long-lasting if dropout rates and learning gaps increase.

KeYwords: COVID-19, school system, distance learning, learning gaps, learning lag, school dropout

ReCEIVED: May 2020 / ACCEPTED: August 2020

\section{INTRODUCCIÓN}

A más de ocho meses de reportarse el primer caso de SARS-CoV-2 en China, todavía sabemos poco sobre este virus. Ante la incertidumbre, el colapso de los sistemas sanitarios ocurrido en varios países del mundo y el alto número de fallecidos, los gobiernos de todas las naciones afectadas han tomado una serie de medidas de contención, mitigación o una mezcla de ambas. Estas medidas permiten disminuir la tasa de contagio del SARS-CoV-2 (Nussbaumer-Streit et al. 2020), pero afectan negativamente otras dimensiones del bienestar de las personas. Los efectos económicos, psicológicos y sociales de las medidas podrían terminar siendo iguales o más dañinos que la propia enfermedad que se busca combatir. ¿Cómo lograr un equilibrio entre la protección a la salud y los efectos adversos de las medidas de contención y mitigación? Solo será posible alcanzar este equilibrio si se logran dimensionar los efectos adversos de las medidas sanitarias y esto es imposible de realizar si no visualizamos las distintas realidades de las familias de nuestro país.

Benítez, Velasco y Vergara (2020) revisan los efectos de las medidas para controlar la pandemia en la economía, salud física y mental de las personas, así como también en otras dimensiones. Este artículo tiene por objeto complementar el trabajo anteriormente citado, incorporando a la discusión los efectos y riesgos del distanciamiento social en el ámbito educativo chileno, en particular, en la educación escolar. A continuación, se busca identificar grupos a nivel nacional que, por sus características, presentan mayores riesgos de sufrir efectos negativos asociados al cierre de los establecimientos escolares, y proponer medidas que permitan aminorar dos de estos efectos: los riesgos de deserción escolar y el aumento de las brechas de aprendizaje. 
Este artículo no pretende agotar la discusión, ni menos ser un catastro exhaustivo de todos los grupos escolares en riesgo en Chile, sino más bien aportar con antecedentes concretos que permitan dimensionar parte de la complejidad que atraviesa la toma de decisiones de las autoridades, así como contribuir con algunas recomendaciones en base a la evidencia comparada. Los datos muestran la precariedad con la que estamos enfrentando el proceso de educación a distancia, lo que probablemente repercutirá en un aumento significativo de la deserción escolar y en el aumento de las brechas de aprendizaje, tanto al interior de las aulas como entre los establecimientos educacionales. La desigual distribución de las habilidades de la tecnología de la información y comunicación (TIC) tanto de docentes como de estudiantes; de las habilidades de comprensión de lectura; del acceso a un computador o Tablet, así como a internet; de la condición de las viviendas, y del capital cultural ${ }^{1}$ de los adultos en el hogar, hace que el impacto de la suspensión de las clases presenciales no se distribuya de forma homogénea en la población nacional escolar, sino que afecte considerablemente más a los niños y jóvenes de hogares con menores recursos, aumentando aún más la inequidad del sistema educativo. Para lograr el objetivo descrito, en la sección siguiente (1) damos cuenta de los riesgos generales asociados a la suspensión de clases presenciales mediante una revisión de la literatura pertinente, para luego caracterizar brevemente a la población infanto-juvenil en Chile (2). Hecho esto, nos enfocamos en el aprendizaje a distancia como consecuencia de la suspensión de las clases presenciales (3). Aquí indagamos tres variables cruciales que afectan positiva o negativamente su logro: las habilidades críticas para el aprendizaje autónomo, las condiciones materiales para el aprendizaje a distancia y el apoyo familiar. Luego, advertimos sobre el eventual aumento de las brechas en los logros de aprendizaje dentro del aula (4), para entonces identificar (5) los grupos de escolares que presentan el mayor riesgo de rezago en los aprendizajes y de desertar del sistema escolar, producto de la suspensión de las clases presenciales. Finalizamos nuestro análisis con recomendaciones de política pública (6) y las conclusiones se presentan en la última sección (7).

\footnotetext{
${ }^{1}$ Este concepto se operacionaliza y estudia de forma concreta mediante su versión 'institucionalizada', cabe decir, mediante el nivel educacional más alto alcanzado por los apoderados. Conceptualmente, el capital cultural es un conjunto de "posiciones, aptitudes, actitudes, preferencias y comportamientos/prácticas culturales que se transmiten e interiorizan a través de y durante los procesos de socialización familiar" (Symeou 2006, 221).
} 


\section{RIESGOS DE LA SUSPENSIÓN DE LAS CLASES PRESENCIALES}

Una de las medidas adoptadas para disminuir el contagio de COVID-19 ha sido la suspensión de clases presenciales en los establecimientos de educación, ya sea parvularia, escolar o superior. Según UNESCO (2020a), en abril de este año, 186 países habían cerrado los establecimientos de educación parvularia, escolar y superior en todo su territorio, nueve países (Australia, China, Dinamarca, Estados Unidos, Groenlandia, Japón, Madagascar, Noruega y Rusia) han focalizado el cierre de establecimientos educacionales y solo tres países continúan con sus establecimientos abiertos (Bielorrusia, Turkmenistán y Tayikistán). En este momento, varios países han ido retornando a una cierta normalidad, pero la amenaza de tener que cerrar nuevamente en caso de rebrotes seguirá presente al menos hasta que exista una vacuna contra el virus. En total, UNESCO estima que 1.725 millones de niños y jóvenes en todo el mundo han visto afectado su proceso de enseñanza por las medidas sanitarias, cifra que corresponde a cerca del $90 \%$ de los jóvenes y niños en el planeta (UNESCO 2020a).

Chile no ha sido la excepción del cierre de los establecimientos educacionales. El domingo 15 de marzo, el gobierno anunció la suspensión de clases presenciales para salas cunas, jardines infantiles, colegios municipales, particulares subvencionados y particulares pagados, la que ha afectado a más de 3,6 millones de estudiantes de acuerdo a datos del Ministerio de Educación (Mineduc) al 2019: más de 600 mil niños en la educación parvularia, 2,9 millones de niños y jóvenes en la educación escolar, casi 200 mil niños en educación especial y 140 mil adultos en programas de educación escolar. Por su parte, las instituciones de educación superior también han suspendido sus clases presenciales, afectando a 1,2 millones de jóvenes, también de acuerdo a cifras del Mineduc a 2019.

La OCDE (2020a) nos advierte de los riesgos que conlleva la suspensión de las clases presenciales, el distanciamiento social y el confinamiento en la población infantil, especialmente en niños de familias vulnerables. Estas medidas tienen un impacto negativo en diversas dimensiones de la vida, como por ejemplo en la alimentación, la convivencia familiar, la salud física y mental, y el desarrollo cognitivo y socioemocional. 
Una buena nutrición es fundamental para un desarrollo físico y cognitivo sano, y su desmedro tiene efectos en el largo plazo sobre la salud y situación económica en la edad adulta (Monckeberg y Valiente 1976; Monckeberg 1988; Britto et al. 2017; Almond, Currie y Duque 2018). En Chile, la Junta Nacional de Auxilio Escolar y Becas (JUNAEB) entrega alimentación al 60\% de los niños que asisten a establecimientos educacionales financiados por el Estado, beneficiando a más de 1,5 millones de niños. El Ministerio de Educación ha hecho un importante esfuerzo por garantizar la distribución de alimentos entre los niños más necesitados, entregando semanalmente canastas alimenticias para 1.517.734 niños. Esta ayuda es fundamental, pero es probable que en el contexto de la crisis económica las raciones alimenticias que entregue el Mineduc sean utilizadas para alimentar a la familia completa y no exclusivamente al estudiante en cuestión; esto, en línea con los estudios de Nord y Romig (2006) y de Morgan et al. (2019), que muestran que los niños con becas alimenticias consumen menos nutrientes durante las vacaciones.

Otra preocupación es el aumento de la violencia intrafamiliar que se ha observado en los últimos meses y, en particular, el maltrato infantil. Las medidas de confinamiento y la recesión económica impactan directamente en los factores que contribuyen a generar estrés tóxico, a saber: cesantía o reducción del ingreso familiar, hacinamiento, distanciamiento social, violencia intrafamiliar y aumento del consumo de drogas y alcohol (Lawson et al. 2017; Bick y Nelson 2016; Brito y Noble 2014; Shonkoff et al. 2009). Entre abril y junio de 2020, las denuncias al fono de orientación del Servicio de la $\mathrm{Mu}-$ jer y Equidad de Género de Chile aumentaron en $200 \%$ en relación con el mismo período del año pasado, mientras que en el caso del maltrato a menores la ONG Activa reportó un aumento de $42 \%$ para abril. $^{2}$ Tanto la UNICEF como la Defensora de la Niñez han advertido que no solo mujeres, sino también niños y adolescentes, están en una situación de mayor riesgo de violencia a causa de las medidas de con-

\footnotetext{
${ }^{2}$ Las cifras de aumento de denuncias al fono de orientación fueron reportadas por $E l$ Mercurio (Marcano 2020) y provienen del Ministerio de la Mujer y Equidad de Género. El aumento de maltrato infantil fue reportado por La Tercera (Morales 2020).
} 
finamiento (Mefalopulos 2020; Morales 2020). Esto es un llamado de alerta, especialmente si consideramos el informe de la Subsecretaría de Prevención del Delito (2017), que estima en 38\% el porcentaje de mujeres que han sido víctimas de violencia en el país, así como datos de la Encuesta Longitudinal de la Primera Infancia (ELPI 2017), que indican que el $62 \%$ de los apoderados usa 'métodos de disciplina violentos' (Mefalopulos 2020) con los niños. La violencia intrafamiliar y el maltrato infantil, junto con otros efectos del confinamiento, pueden generar estrés tóxico en los niños y adolescentes, que a su vez pueden causar problemas de salud mental permanentes. Esto es especialmente relevante para la población infantil, dado que la salud mental es el principal problema que afecta a los jóvenes (Burns y Gottschalk 2019). Estudios basados en el brote epidémico del SARS en 2003, muestran que el confinamiento y el cierre de escuelas produjo un aumento de ansiedad, depresión y estrés postraumático en los niños (Sprang y Siman 2013; Hawryluck et al. 2004). Según el Institute for Health Metrics and Evaluation (IHME 2020), la prevalencia de enfermedades mentales entre menores de 20 años en Chile es cercana a $14 \%$, una de las más altas entre los países de la OCDE.

Finalmente, las medidas sanitarias también han afectado el proceso de aprendizaje de los niños y jóvenes, perjudicando especialmente a quienes provienen de las familias más vulnerables. La escuela cumple un rol fundamental en equiparar las oportunidades de aprendizaje al asegurar, al interior del establecimiento educacional, condiciones iguales para todos. En el aprendizaje a distancia se atenúa la influencia del establecimiento y las condiciones del hogar se vuelven aún más determinantes. Las familias de menores ingresos enfrentan los mayores obstáculos en el aprendizaje a distancia. La carencia de condiciones físicas apropiadas para el estudio, tales como hacinamiento, calefacción inadecuada, ruido, ausencia de herramientas digitales (computador, Tablet, smartphone), así como la falta de acceso a internet, junto con las diferencias en capital humano (disponibilidad de adultos para el acompañamiento y reducido capital cultural de los adultos), juegan un rol crucial en el proceso de aprendizaje a distancia. Investigaciones sobre el efecto de las vacaciones, es decir, de períodos prolongados fuera de las aulas, muestran caídas en los conocimientos de matemática y, en menor medida, en la comprensión de lectura, las cuales son más pronunciadas en 
los grupos de menores recursos ${ }^{3}$ (Cooper et al. 1996; Quinn y Polikoff 2017; Kuhfeld y Soland 2020). Por ello, los establecimientos educacionales de todo el mundo han buscado adecuarse al desafío, moviéndose hacia la enseñanza a distancia durante el confinamiento, y los países del hemisferio norte han mostrado especial preocupación por la apertura de sus recintos escolares.

Para Chile y los países del hemisferio sur, que recién habían retornado a clases después de las vacaciones de verano, el desafío es aún mayor. Un nuevo período fuera de las aulas podría acentuar la tendencia de pérdidas en conocimientos y destrezas matemáticas ocurridas durante las vacaciones. Además, al llevar poco tiempo de clases, es probable que los estudiantes aún se estuvieran ajustando a la rutina escolar y, en muchos casos, los profesores recién estuvieran conociendo a sus estudiantes, sobre todo en los cursos iniciales de los diferentes ciclos. A ello se suman las desigualdades materiales de los hogares para enfrentar el aprendizaje a distancia, y el bajo nivel de alfabetización digital de los estudiantes y docentes que se revelan en este estudio.

Junto con el aumento de las brechas de aprendizaje se corre el riesgo de aumentar significativamente el número de niños excluidos del sistema escolar. Según cifras oficiales del Ministerio de Educación (2020), en Chile, cerca de 185 mil niños y jóvenes se encuentran excluidos de la educación escolar, y el Mineduc estima que este número podría aumentar hasta en $40 \%$ a causa de la suspensión de clases, el rezago en los aprendizajes y la recesión económica.

A pesar de las diversas implicancias de este contexto, en este artículo nos enfocaremos únicamente en la dimensión de los aprendizajes y la deserción escolar. Nos interesa analizar, a partir de los datos disponibles, las condiciones de los estudiantes y de los establecimientos escolares para abordar la educación a distancia, con el objeto de identificar los grupos de mayor riesgo y de entregar orientaciones a quienes toman las decisiones para mitigar los adversos efectos de la suspensión de clases presenciales y minimizar los riesgos una vez concretado el retorno. Utilizamos para ello los datos más recientes que nos permitan caracterizar a estos grupos: CASEN 2017, SIMCE 2017 y 2018 (cuestionarios

\footnotetext{
${ }^{3}$ Evidencia sobre la caída en el progreso en matemáticas producto del cierre de establecimientos en Estados Unidos replica estos resultados con caídas entre los grupos de menores ingresos (Jochim 2020; The Economist 2020).
} 
a padres, estudiantes y profesores), y evaluación ICILS 2018 (que mide competencias digitales entre jóvenes de octavo básico y recopila antecedentes de sus docentes). ${ }^{4}$

\section{CARACTERIZACIÓN DE LA POBLACIÓN INFANTO-JUVENIL}

A nivel nacional, en base a CASEN 2017, el 23\% de la población en Chile tiene menos de 18 años (4,1 millones de niños y jóvenes). Ellos no se distribuyen homogéneamente según nivel de ingresos del hogar; mientras el $29 \%$ se ubica en el quintil de menores ingresos, solo el $10 \%$ se ubica en el de mayores ingresos. Los hogares de menores ingresos no solo presentan una mayor probabilidad que los hogares de altos ingresos de tener al menos un menor de 18 años, sino que en promedio tienen más niños. Por ello, dado que los quintiles de ingresos se calculan a nivel de hogar, se observa una mayor concentración de menores de 18 años en los quintiles de menores ingresos. ${ }^{5}$ En contrapartida, los mayores de 18 años evidencian una menor concentración en los quintiles de menores ingresos, como muestra el Gráfico 1.

\footnotetext{
${ }^{4}$ La Encuesta de Caracterización Socioeconómica Nacional (CASEN) es realizada por el Ministerio de Desarrollo Social y Familia (MDSF, antes Ministerio de Planificación y Cooperación) desde 1987 en forma periódica. La CASEN entrega información representativa a nivel nacional, regional y urbano rural. Se realiza mediante entrevistas cara a cara y recoge información de todos los integrantes de las viviendas, las que son seleccionadas mediante un diseño complejo de manera probabilística, estratificada y multietápica (MDSF 2020, 8-9). SIMCE corresponde al Sistema de Medición de la Calidad de la Educación que se realiza en forma censal todos los años entre cuarto básico y segundo medio, y en años alternados a sexto y octavo básico, en las áreas de lenguage y matemáticas, y en evaluaciones alternadas desde sexto básico en ciencias sociales y ciencias naturales. Para mayor detalle ver https://www.agenciaeducacion.cl/evaluaciones/que-esel-simce/ [ 1 de julio]. ICILS 2018 es la segunda instancia del International Computer and Information Literacy Study en la que participa Chile, explicado en el cuerpo del texto más adelante.

${ }^{5}$ Según CASEN 2017, el 57\% de los hogares del quintil de menores ingresos tiene al menos un menor de 18 años, en comparación con el $27 \%$ de los hogares del quintil de mayores ingresos. El número de niños por hogar también es mayor en los quintiles de menores ingresos. Mientras el $64 \%$ de los hogares del primer quintil tiene al menos dos menores de 18 años, solo el 34\% del quinto quintil tiene dos o más menores. La diferencia es aún más pronunciada cuando consideramos los hogares con tres o más menores de edad: $28 \%$ de los hogares del primer quintil versus $8 \%$ de los hogares del quinto quintil.
} 
Gráfico 1. MENORES Y MAYORES DE 18 AÑOS SEGÚN QUINTIL DE INGRESO DEL HOGAR

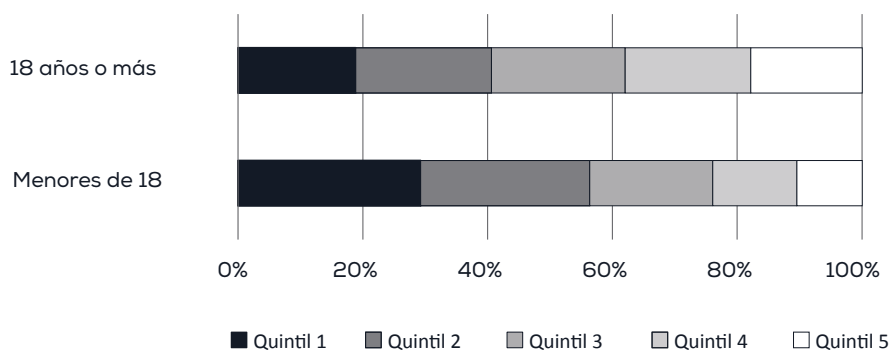

Fuente: Elaboración propia en base a Casen 2017.

La cobertura escolar en Chile en comparación con la del resto de América Latina es alta (Banco Mundial 2018). En la Enseñanza Básica, la cobertura es cercana al $100 \%$, mientras en la Enseñanza Media la tasa bruta es de $89 \%$, según datos para 2016 del Mineduc (Centro de Estudios Mineduc 2018). ${ }^{6}$ En la Enseñanza Media se observa una gran diferencia en cobertura entre los grados inferiores y los superiores. Mientras la cobertura bruta en primero y segundo medio supera el $90 \%$ del total de jóvenes en ese rango de edad, en tercero medio disminuye a $83 \%$ y en cuatro medio es $74 \%$. La cobertura por edad muestra que sobre el $90 \%$ de los jóvenes menores de 18 años asiste a un establecimiento educacional, de manera que la deserción se da principalmente entre los jóvenes mayores de 17 años que no han terminado la educación obligatoria, probablemente debido a repitencia escolar. De hecho, $19 \%$ de los jóvenes entre 18 y 20 años no ha terminado la enseñanza escolar. Entre quienes no han terminado la Enseñanza Media, un 52\% no asiste a un establecimiento escolar. Este grupo de jóvenes se concentra

\footnotetext{
${ }^{6}$ La educación escolar en Chile se divide en dos etapas: el nivel de Enseñanza Básica, de ocho años de duración, y la Enseñanza Media, de cuatro años de duración, ambos niveles obligatorios. En términos administrativos, los establecimientos se distribuyen en tres categorías según dependencia o propiedad: educación municipal, particular subvencionada y particular pagada. Las dos primeras se financian a través de subvenciones del Estado. Cabe mencionar que en 2017 fue promulgada la ley que creó una nueva institucionalidad para la educación municipal: los servicios locales de educación. A julio de 2020 se han traspasado establecimientos de 25 comunas a siete servicios locales de educación. Más información disponible en: https://educacionpublica.cl/ [1 de julio 2020].
} 
en los quintiles de menores ingresos (66\% proviene de hogares pertenecientes al 40\% de menores ingresos, CASEN 2017).

En relación con la dependencia administrativa de los establecimientos escolares, 53\% de los niños cursa la Enseñanza Básica en un colegio particular subvencionado, $37 \%$ en uno municipal y $10 \%$ en uno particular pagado. En la Enseñanza Media, la distribución es similar: $51 \%$ de los jóvenes asiste a un colegio particular subvencionado, 34\% a un liceo municipal, $10 \%$ a un colegio particular pagado y $5 \%$ a liceos del Estado, cuya administración ha sido delegada en sostenedores privados. A nivel curricular, el $73 \%$ de los estudiantes sigue un currículo humanista-científico en la Enseñanza Media, frente al 27\% que sigue el currículo técnico-profesional (Mineduc 2019). En el mundo técnicoprofesional, prácticamente no hay presencia de colegios particulares pagados, mientras que en el humanista-científico los colegios particulares pagados abarcan el 13\% de los estudiantes. Los estudiantes de mayores ingresos se concentran en los colegios particulares pagados, mientras que los establecimientos municipales concentran en mayor medida a los estudiantes más vulnerables. Los establecimientos particulares subvencionados también concentran a estudiantes vulnerables, pero en menor medida que los establecimientos municipales. Los liceos técnicosprofesionales concentran una mayor proporción de alumnos vulnerables que los establecimientos humanista-científicos.

\section{APRENDIZAJE A DISTANCIA}

Desde el lunes 16 de marzo, los establecimientos escolares debieron volcarse a la enseñanza a distancia y a la fecha de publicación de este artículo, aún no está claro cuándo podrán retomarse las clases presenciales. La encuesta realizada a principios de junio por el Ministerio de Educación muestra que casi la totalidad de los establecimientos ha entregado materiales pedagógicos para dar continuidad al aprendizaje. La gran mayoría (83\%) los entrega tanto en forma física como vía online, lo que corresponde al $86 \%$ de la matrícula total. ${ }^{7}$ A nivel nacional, un

\footnotetext{
${ }^{7}$ Encuesta online realizada por el Centro de Estudios del Ministerio de Educación que contó con una tasa de respuesta global del 58\% de los establecimientos (Centro de Estudios Mineduc 2020).
} 
$7 \%$ de los establecimientos solo distribuye materiales vía online, mientras un $10 \%$ lo realiza solo en forma física, lo que corresponde a un $11 \%$ y $2 \%$ de la matrícula, respectivamente.

Aun cuando el establecimiento entregue materiales a los niños, el aprendizaje a distancia requiere ciertas condiciones materiales y apoyo para que funcione adecuadamente (UNESCO 2020b). También juega un rol la presencia de profesores capacitados, así como la interacción entre pares y con profesores (Rice 2006). Además del apoyo entregado por el establecimiento, es necesario que los niños y jóvenes cuenten con un espacio adecuado y, sobre todo en el caso de los niños pequeños, con el involucramiento de un adulto que pueda supervisar el aprendizaje (Rice 2006). Por otra parte, las posibilidades de aprendizaje también dependerán de las competencias con que los estudiantes cuentan, tales como, por ejemplo, el nivel de comprensión lectora, las herramientas computacionales, la autoeficacia en el uso de tecnología y los hábitos de estudio (Roblyer et al. 2008). De hecho, un poco menos de la mitad de los directivos de establecimientos del país (46\%) cree que al menos un $80 \%$ de sus estudiantes está utilizando alguna de las herramientas analizadas, tales como guías de estudios. Y un 15\% piensa que menos de la mitad lo está haciendo (Centro de Estudios Mineduc 2020). Así también "La mirada de los docentes" $(2020),{ }^{8}$ realizada la última quincena de abril, muestra que solo el $49 \%$ de los docentes encuestados cree que sus estudiantes están aprendiendo. Las desigualdades en las diferentes dimensiones interactúan con las diversas capacidades que tienen los establecimientos escolares para abordar la educación a distancia. Si los estudiantes con mayores carencias pertenecen a establecimientos con menores capacidades para la enseñanza a distancia, las desigualdades pueden exacerbarse.

En lo que sigue, revisaremos cómo se encuentran los escolares chilenos con respecto a estas diferentes condiciones, en particular en relación con sus habilidades lectoras y con el manejo de tecnología. Esto permitirá dimensionar la magnitud del desafío, así como identificar los grupos que requieren de una intervención con mayor urgencia.

\footnotetext{
${ }^{8}$ Encuesta online realizada entre el 17 y el 28 de abril de 2020. Según detalla el informe, se obtuvo una tasa de respuesta bruta (sin excluir a quienes no son docentes de aula sino que ejercen otras funciones) de $12 \%$. De los 3.176 docentes de aula que respondieron la encuesta, $50 \%$ de ellos se desempeña en establecimientos municipales, $43 \%$ en particular subvencionados y el restante $7 \%$ en establecimientos particulares pagados. Para más detalle, ver informe en www.miradadocentes.cl [1 de julio 2020].
} 


\section{Habilidades críticas para el aprendizaje a distancia}

El aprendizaje a distancia implica una mayor exigencia para los estudiantes, en cuanto deben trabajar de forma más autónoma. En este contexto, la comprensión lectora se vuelve aún más determinante en las oportunidades de aprendizaje. En Chile, los estándares de aprendizaje de la prueba SIMCE de Lectura permiten dimensionar qué proporción de los estudiantes no es capaz de alcanzar una comprensión global de lo leído, realizar inferencias y reflexionar sobre la lectura (Unidad de Currículum y Evaluación 2013, 2015). En 2018, el 29\% de los alumnos de cuarto básico se encontraba en un nivel insuficiente de lectura; esa proporción aumenta en los niveles superiores. Así, el 37\% de los escolares de sexto básico y el $50 \%$ de los estudiantes de segundo medio se encuentran en este nivel (Gráfico 2).

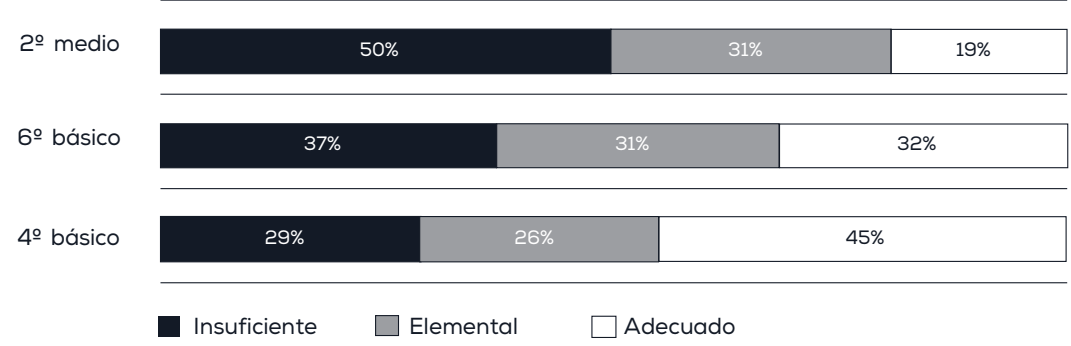

Fuente: Elaboración propia en base a SIMCE 2018 para cuarto y sexto básico, y segundo medio.

Los escolares ubicados en el estándar de aprendizaje insuficiente difícilmente podrán seguir aprendiendo mediante la lectura independiente en sus hogares. En los tres niveles evaluados, la proporción de estudiantes en el nivel insuficiente es mayor en sectores rurales. Además, los estudiantes de nivel insuficiente se concentran en establecimientos municipales y en hogares donde los padres tienen menos años de escolaridad. Si bien existen diferencias según el nivel de enseñanza, en todos observamos este mismo patrón (Gráfico 3A). Entre los escolares de cuarto básico, cuyos padres no tienen Enseñanza Media completa, el $44 \%$ se encuentra en la categoría insuficiente y solo el $28 \%$ 
alcanza el nivel adecuado. En contraposición, 21\% de los estudiantes de cuarto básico con padres con educación superior se encuentra en el nivel insuficiente, mientras que el 54\% se ubica en el nivel adecuado. En los cursos superiores aumenta la proporción de estudiantes en el nivel insuficiente, manteniéndose brechas importantes según el nivel de educación de los padres. A nivel de dependencia administrativa, se observa que las brechas entre estas son mayores que las observadas por nivel educacional de los padres, como se advierte en el Gráfico 3B. ${ }^{9}$

Un segundo factor a considerar para el aprendizaje a distancia es el nivel de habilidades tecnológicas que han desarrollado los estudiantes. El estudio ICILS 2018 permite evaluar la capacidad de los estudiantes en el uso de computadores para investigar, crear y comunicarse. ${ }^{10}$ Entre los 13 países que participaron del estudio, Chile se ubica en el grupo de peor desempeño junto con Luxemburgo, Italia, Uruguay y Kazajistán, alcanzando en promedio el nivel más básico de habilidades en tecnologías de la información y la comunicación (TIC). En el Gráfico 4 se representa el desempeño de los países, distribuyendo a los estudiantes por nivel de habilidades. Dado que desde el nivel 3 en adelante los estudiantes cuentan con un desarrollo adecuado de habilidades tecnológicas, se ha centrado en ese nivel. Hacia la derecha se muestra la proporción en ese nivel o superior, y hacia la izquierda, la proporción de estudiantes que no alcanza ese nivel mínimo. Más allá de las comparaciones internacionales, resulta preocupante que el $20 \%$ de los estudiantes de octavo básico no tenga familiaridad con el rango básico de comandos y programas para realizar tareas rutinarias (por ejemplo, abrir una nueva pestaña de un navegador o insertar una imagen en un docu-

\footnotetext{
${ }^{9} \mathrm{Al}$ mirar estas diferencias, distinguiendo entre sectores rurales y urbanos, vemos que estos patrones se mantienen y, en general, el desempeño es menor en los sectores rurales. Cabe notar que esta diferencia es mayor entre los establecimientos particulares subvencionados que entre los municipales en todos los niveles. El número de establecimientos particulares pagados en zona rurales es muy pequeño: cerca de 80 a nivel nacional.

${ }^{10}$ El estudio establece cuatro niveles: 1) manejo funcional básico de los computadores como herramientas; 2) uso del computador para completar tareas básicas de recopilación y manejo de información, bajo instrucciones directas y explícitas; 3) manejo del computador para reunir y gestionar información de manera independiente; y 4) aplicar criterios de pertinencia y confiabilidad al recopilar información y crear productos informativos de forma independiente. Ver Fraillon et al. (2020).
} 
Gráfico 3A. ESTÁNDAR DE APRENDIZAJE LECTURA SIMCE 2018, SEGÚN GRADO DE ENSEÑANZA Y NIVEL DE EDUCACIÓN DE LOS PADRES

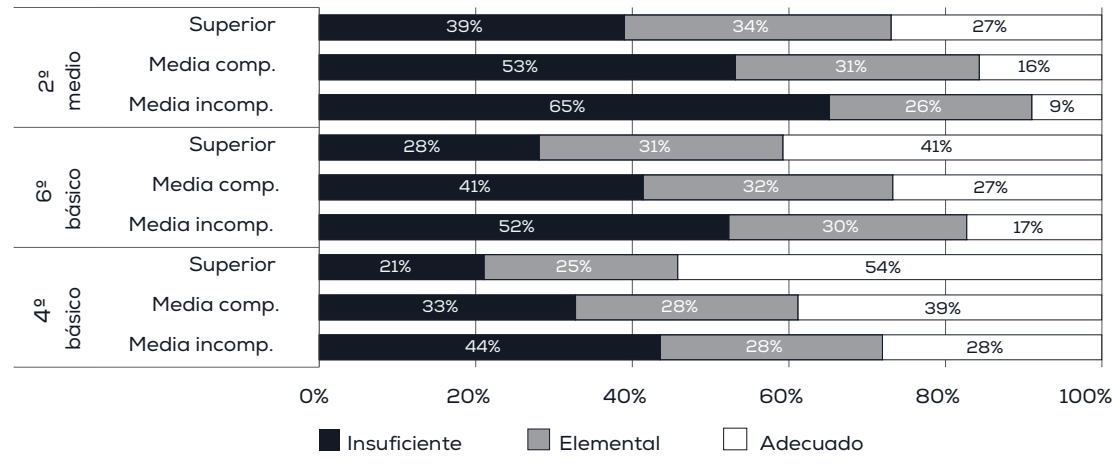

Fuente: Elaboración propia en base a SIMCE 2018 para cuarto y sexto básico, y segundo medio.

Gráfico 3B. ESTÁNDAR DE APRENDIZAJE LECTURA SIMCE 2018, SEGÚN GRADO DE ENSEÑANZA Y DEPENDENCIA ADMINISTRATIVA DEL ESTABLECIMIENTO

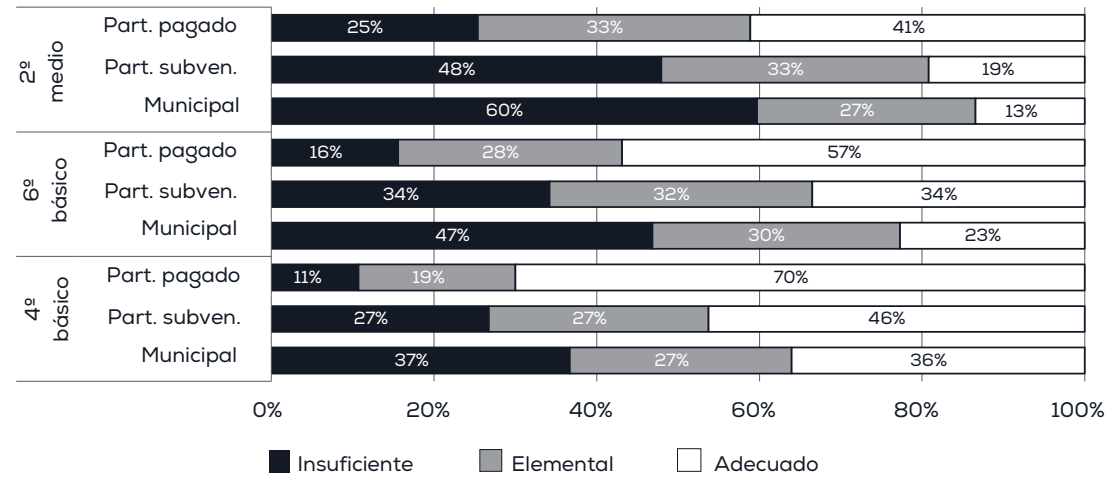

Fuente: Elaboración propia en base a SIMCE 2018 para cuarto y sexto básico, y segundo medio.

mento), y para el $90 \%$ de los estudiantes de octavo básico la enseñanza online será un desafío mayor, ya que no evidencian haber adquirido las destrezas y conocimientos suficientes para usar de forma independiente un computador como herramienta para recopilar y manejar información (ICILS 2018). 
Gráfico 4. DISTRIBUCIÓN POR NIVEL DE HABILIDADES TIC ALCANZADO EN PRUEBA INTERNACIONAL ICILS 2018

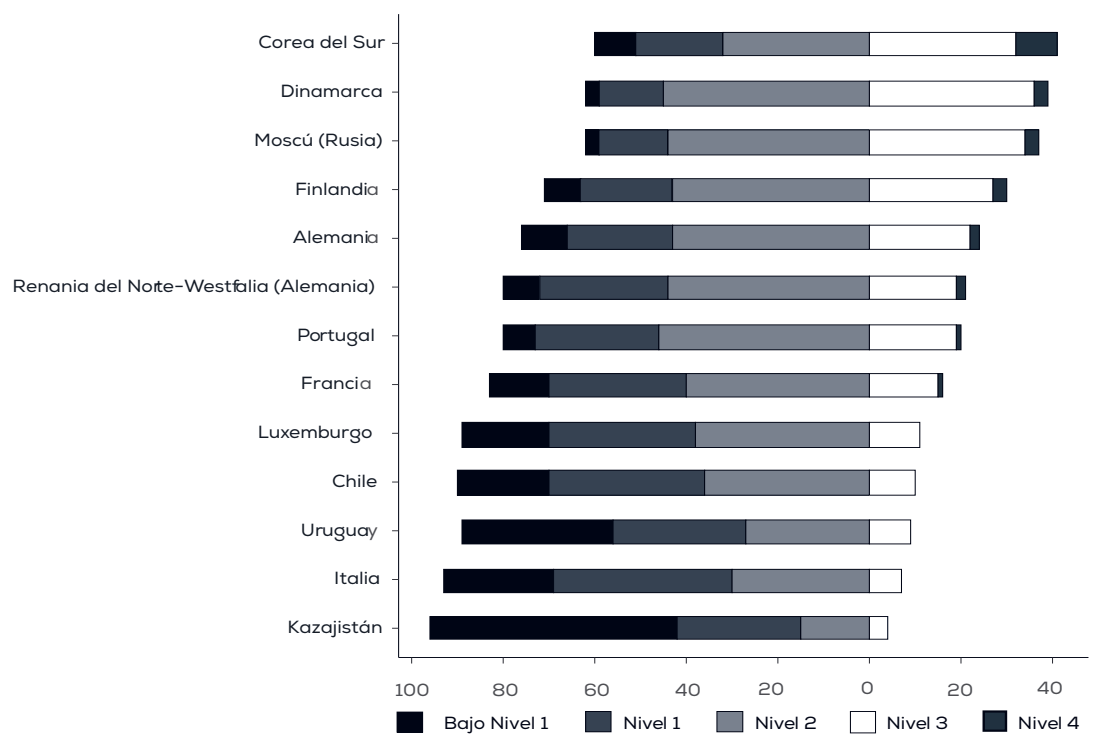

Fuente: Informe internacional ICILS 2018.

Tanto en ICILS 2018 como en otras evaluaciones internacionales (OCDE 2016), se advierte una asociación entre nivel socioeconómico y puntaje del estudiante. En comparación con los otros países, la brecha socioeconómica en Chile tiende a ser de las más altas (ICILS 2018). En el estudio se observa también que los estudiantes de zonas rurales tienen en promedio menos habilidades de computación que los de zonas urbanas, patrón similar al observado en las pruebas SIMCE. Así, el puntaje promedio para ICILS en zonas rurales es de 430 puntos, en contraste con un promedio de 480 puntos para zonas urbanas.

Estas destrezas, como es de esperar, están relacionadas con el bajo uso de TIC para actividades relacionadas con el colegio. En 2018, más de la mitad de los estudiantes de octavo básico había utilizado ninguna o menos de una vez al mes el computador para completar ejercicios o guías, para aprender habilidades o rendir pruebas. 
Gráfico 5. FRECUENCIA EN USO DE TIC PARA ACTIVIDADES RELACIONADAS CON EL COLEGIO (OCTAVO BÁSICO)

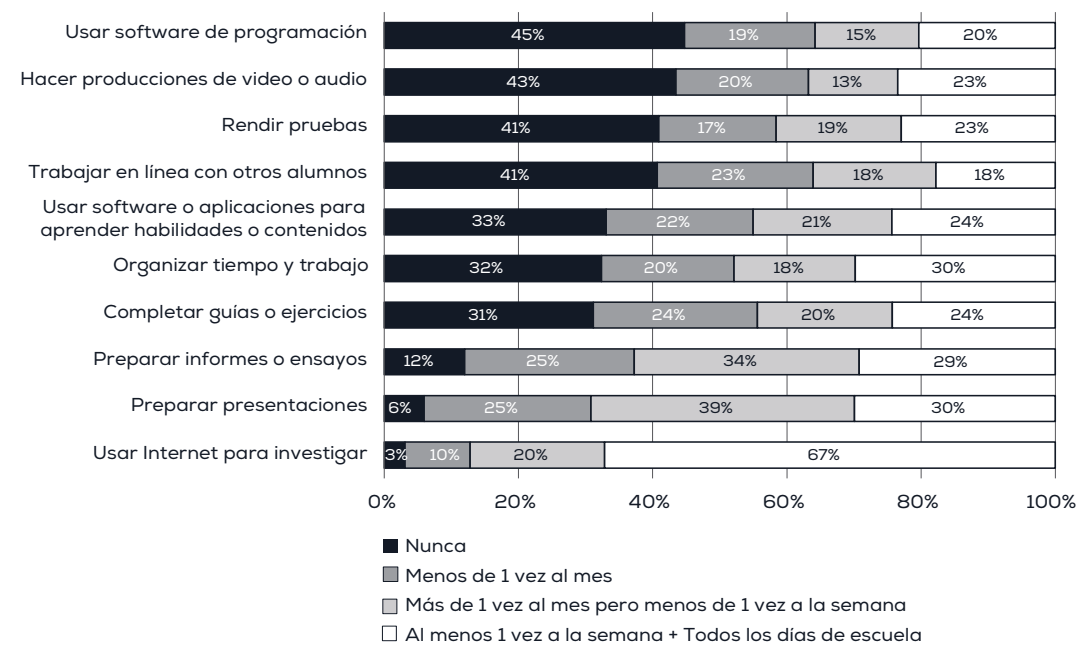

Fuente: Elaboración propia en base a datos ICILS 2018.

Finalmente, también inciden en el aprendizaje a distancia los hábitos de estudio de los estudiantes. Algunas preguntas del cuestionario SIMCE a estudiantes entregan luces respecto de la motivación de los estudiantes para realizar tareas o leer. Según los resultados del SIMCE 2018, el 73\% de los alumnos de segundo medio declara realizar sus tareas y el $40 \%$ cuenta con hábitos de lectura, ${ }^{11}$ porcentajes que no varían de acuerdo a la dependencia administrativa. Si bien esta proporción parece alta, las percepciones de los docentes muestran una realidad más preocupante. Según la encuesta "La mirada de los docentes" (2020), el 91\% de los docentes considera que la mayoría de sus estudiantes no tiene hábitos de estudio y el $75 \%$ estima que ellos no cuentan con las habilidades necesarias para usar aplicaciones de trabajo a distancia.

En resumen, considerando que la capacidad de lectura se vuelve aún más relevante para el aprendizaje a distancia, se encuentra que la mitad de los estudiantes de segundo medio difícilmente podrá apoyarse en ella, pues presenta grandes dificultades en compresión lectora, situándose en el estándar insuficiente, como se vio en el Gráfico 3. En

\footnotetext{
${ }^{11}$ Los jóvenes responden que están de acuerdo o muy de acuerdo con la afirmación 'La lectura es uno de mis pasatiempos favoritos'.
} 
los cursos inferiores, el porcentaje con nivel insuficiente es menor, pero aun así alcanza magnitudes preocupantes: $29 \%$ en cuarto básico y $27 \%$ en sexto básico; es decir, más de uno de cada cuatro estudiantes se ubica en ese nivel. Este grupo tiende a tener padres con menores niveles de educación y se concentra en establecimientos municipales y particulares subvencionados. Si sumamos a esas dificultades las destrezas tecnológicas, las cuales también se encuentran asociadas al nivel de educación de los padres, se constata que existe un doble riesgo para los escolares en nivel insuficiente.

\section{Condiciones de la vivienda para el aprendizaje a distancia}

Existe evidencia respecto de cómo las condiciones físicas del hogar inciden en los aprendizajes y estas se vuelven críticas cuando todo el proceso de aprendizaje se realiza a distancia (Evans 2006; Ferguson et al. 2013; Clair 2019). En Chile, el 9\% de la población vive en condición de hacinamiento, pero esta proporción aumenta entre la población escolar. Según los datos de la CASEN 2017, ${ }^{12}$ cerca de 380 mil escolares menores de 18 años viven en condiciones de hacinamiento, que corresponde al $15 \%$ de los escolares. Estos niños y jóvenes se concentran en los dos primeros quintiles de ingreso (78\%). Ellos conforman uno de los principales grupos de riesgo, pues no solo carecen de las condiciones materiales mínimas que supone el aprendizaje a distancia, sino también a causa del estrés psicológico que produce el encierro prolongado en espacios pequeños como puede ser el hogar, lo cual puede generar un aumento de la violencia intrafamiliar (Corral-Verdugo et al. 2011).

Otro factor que incide en las condiciones físicas del hogar es la materialidad de la vivienda y el estado de esta. El Ministerio de Desarrollo Social y Familia elabora un índice de calidad global de la vivienda en función de la materialidad, tipo de vivienda y acceso a servicios básicos. El 87\% de la población reside en viviendas en estado aceptable, mientras que el $12 \%$ lo hace en aquellas calificadas como recuperables y que por tanto presentan "alguna necesidad de mejoramiento,

\footnotetext{
12 Para todas las estimaciones a partir de la encuesta CASEN 2017, se siguen las recomendaciones para su reporte. En concreto, se indican los casos en que las estimaciones no cumplen los criterios de número de casos y coeficiente de variación recomendados en el Manual del Investigador (MDSF 2018).
} 
reparación o adecuación" (MDSF 2018, 20). Solo el 1\% de la población vive en viviendas irrecuperables. Cabe destacar que, si bien la mayor parte de los estudiantes (sobre un $80 \%$ ) habita en viviendas de calidad aceptable, el 74\% de los que residen en viviendas recuperables e irrecuperables pertenece a los dos quintiles de menores ingresos.

Combinando tanto el nivel de hacinamiento como la calidad global de la vivienda, encontramos que el $25 \%$ de los escolares a nivel nacional presenta algún tipo de carencia habitacional, ya sea por el nivel de hacinamiento o por la calidad de la vivienda, o ambas. Pero, mientras en el quintil de mayores ingresos solo el $6 \%$ de los escolares presenta carencias en esta dimensión, el 38\% de los escolares del primer quintil se encuentra en esa condición de desventaja, como lo muestra el Gráfico 6.

Gráfico 6. CONDICIÓN DE HACINAMIENTO Y CALIDAD DE LA VIVIENDA DE LOS ESTUDIANTES, SEGÚN QUINTILES DE INGRESO DEL HOGAR Y TOTAL NACIONAL

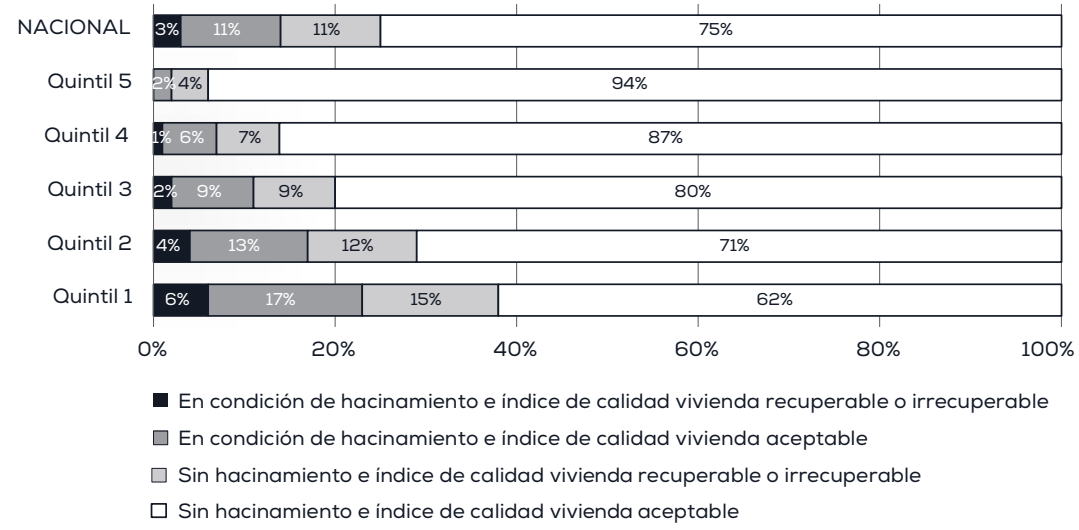

Fuente: Elaboración propia en base a CASEN 2017.

Nota: La proporción estimada de escolares en condición de hacinamiento e índice de calidad de vivienda recuperable o irrecuperable de los quintiles 3, 4, y 5, no cumplen con los criterios de número de casos y con el coeficiente de variación recomendados por el MDSF (2018). Así tampoco los dos grupos siguientes del quintil 5.

Existe un segundo grupo de riesgo, a saber, los niños y jóvenes que no tienen acceso a internet o no cuentan con un computador o Tablet, herramientas básicas para la educación a distancia. Un nivel de acceso mínimo consiste en contar al menos con un computador en la vivien- 
da. ${ }^{13}$ Claramente, su disponibilidad dependerá de cuántas personas necesiten utilizarlo. Por lo tanto, los valores mostrados en el siguiente análisis quizás sobreestimen el acceso y constituyen así un escenario optimista respecto de la situación de los escolares. Si miramos las características de los hogares de los estudiantes a partir de la encuesta CASEN 2017, se observa que el 29\% de ellos no cuenta con al menos un computador en su vivienda y el 13\% de los escolares no cuenta con acceso a internet de ningún tipo. ${ }^{14} \mathrm{Si}$ consideramos ambos factores (internet y computador), el $9 \%$ no cuenta ni con computador ni con acceso a internet en su vivienda. Como muestra el Gráfico 7, mientras más de la mitad de los escolares del primer quintil no cuenta con acceso a ambas herramientas en su vivienda (53\%), apenas el $4 \%$ del quintil de mayores ingresos no tiene acceso a ambas.

Si consideramos tanto las condiciones de la vivienda (nivel de hacinamiento y materialidad) como las de equipamiento (acceso a internet y computador), el 53\% de los escolares cuenta con las condiciones físicas mínimas para el aprendizaje a distancia. Esta proporción probablemente sobreestima la proporción de estudiantes con condiciones mínimas. Esto, ya que no considera la disponibilidad del computador para el escolar, sino solo la existencia de al menos uno en su vivienda, por lo que su uso puede estar limitado por la necesidad de compartirlo con otros adultos o escolares dentro de la vivienda. También considera acceso a internet, ya sea por banda ancha fija o móvil, o bien, desde el celular de alguna persona de su vivienda, por lo que no contempla la calidad de la señal. En ese sentido, es ilustradora la encuesta "La mirada de los docentes" (2020), que revela que solo el 33\% de los docentes encuestados cree que sus estudiantes cuentan con el espacio físico y recursos para estudiar. Las condiciones de la vivienda, así como el acceso a internet y computador son sumamente desiguales según el nivel de ingresos familiares: mientras el $90 \%$ de los escolares del quintil de mayores ingresos cuenta con las condiciones adecuadas, solo el $32 \%$

\footnotetext{
${ }^{13}$ Este cálculo se realiza a nivel de vivienda y, por tanto, si hay dos hogares en una misma vivienda y al menos uno de ellos cuenta con un computador, se considera que todos los escolares que residen allí, pertenezcan o no a ese hogar, cuentan con al menos un computador en la vivienda.

${ }^{14}$ Cabe destacar que solo se considera el acceso a internet sin distinguir el tipo de conexión. Si se considera solo el acceso a internet de banda ancha fija, menos de la mitad de los escolares cuenta con ella en su vivienda (47\%).
} 
Gráfico 7. ACCESO A INTERNET Y COMPUTADOR EN ESTUDIANTES, SEGÚN QUINTIL DE INGRESO DEL HOGAR Y TOTAL NACIONAL

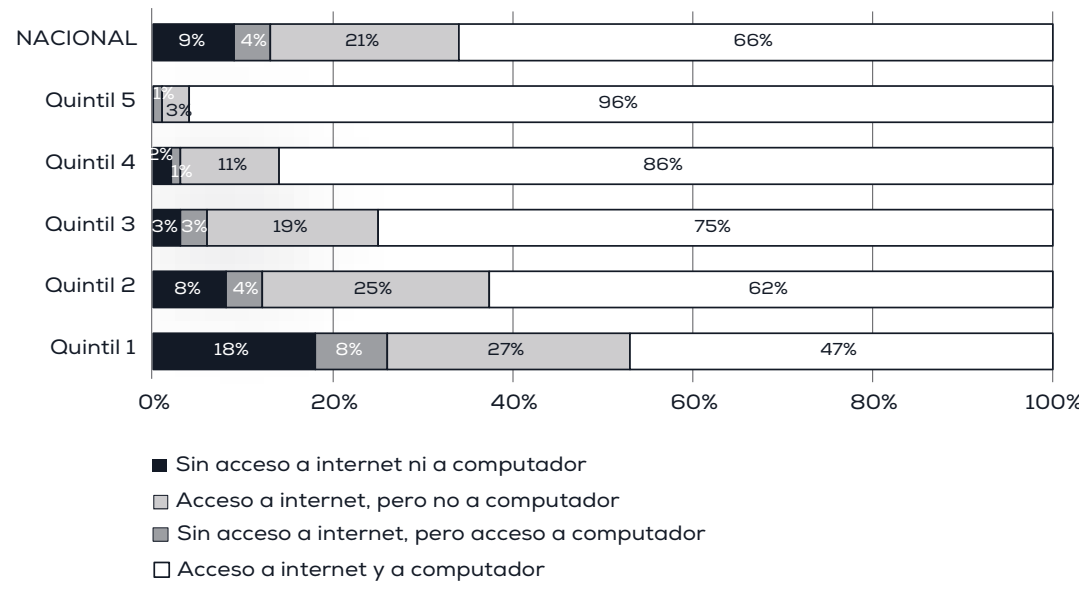

Fuente: Elaboración propia en base a CASEN 2017.

Nota: La proporción estimada de escolares sin acceso a internet (ya sea con o sin acceso a computador) de los quintiles 4 y 5 no cumple con los criterios recomendados por el MDSF (2018), así como tampoco la proporción estimada de estudiantes del último quintil con acceso a internet, pero no a computador.

de los de menores ingresos las tienen, como muestra el Gráfico 8. Por otra parte, mientras casi uno de cada cuatro escolares del primer quintil tiene carencias tanto habitacionales como de equipamiento, uno de cada cien escolares del quintil de mayores ingresos presenta ambas carencias.

Diferencias en acceso y por lo tanto en uso habitual, se asocian a diferencias en habilidades TIC (Roschelle et al. 2010; O'Dwyer et al. 2005), las que también se observan en los resultados del SIMCE 2018 y en la prueba ICILS 2018. ${ }^{15}$ Estos resultados indican que los escolares que necesitan más apoyo en el uso de las herramientas digitales durante

\footnotetext{
${ }^{15}$ En 2017, el 12\% de los alumnos de segundo medio que se encontraba en el nivel insuficiente de lectura, declaraba no tener acceso a internet en el hogar, en contraste con el $8 \%$ de quienes se encontraban en el nivel elemental y con el $5 \%$, en el nivel adecuado. Asimismo, los estudiantes de octavo básico que no contaban con acceso a internet evaluados en la prueba ICILS 2018 (16\%), son los que obtuvieron un menor nivel de desempeño en la prueba.
} 
Gráfico 8. DISTRIBUCIÓN DE ESTUDIANTES DE ACUERDO A CONDICIONES MATERIALES PARA EL APRENDIZAJE, SEGÚN QUINTIL DE INGRESO DEL HOGAR Y TOTAL NACIONAL

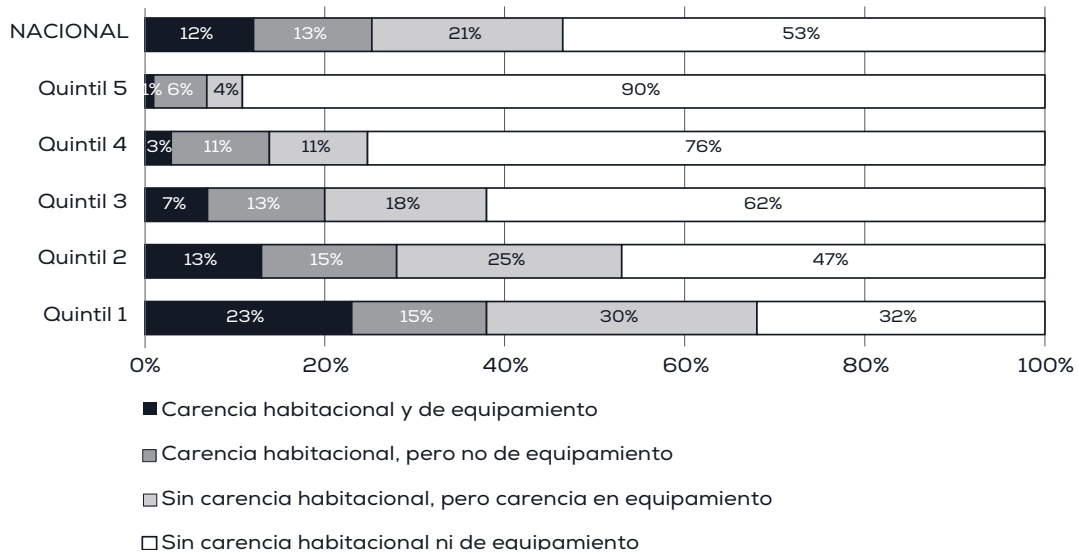

Fuente: Elaboración propia en base a CASEN 2017.

Nota: La proporción estimada de escolares del quintil 5 con carencia habitacional y de equipamiento, asi como con carencia habitacional, pero no de equipamiento, no cumple con los criterios recomendados por el MDSF (2018).

el aprendizaje a distancia, tienen mayores dificultades para acceder a dicho apoyo.

Las condiciones materiales de nuestros escolares están lejos de ser las óptimas para el aprendizaje a distancia, incluso en un escenario optimista y pensando que en los tres años desde que se levantaron los datos de la encuesta CASEN, el acceso puede haberse ampliado. Los datos nos advierten que casi la mitad de los escolares a nivel nacional no cuenta con las condiciones materiales adecuadas para el aprendizaje a distancia. Estas condiciones se distribuyen de manera muy desigual en relación con los ingresos del hogar: mientras el $90 \%$ de los escolares del quintil de mayores ingresos cuenta con las condiciones mínimas en equipamiento y vivienda, solo el $32 \%$ de los escolares pertenecientes al quintil de menores ingresos se encuentra en esa situación. Estas diferencias en las condiciones básicas para el aprendizaje a distancia probablemente tendrán un efecto negativo sobre las actuales brechas de aprendizaje, aumentando aún más las diferencias en logros de aprendizaje entre los niños en función de su nivel socioeconómico. Además, 
ante la mayor dificultad para continuar con el proceso de aprendizaje debido a las limitaciones materiales, puede aumentar la desmotivación y, por ende, de deserción escolar.

\section{Apoyo familiar en el proceso de aprendizaje a distancia}

En momentos en que ya no existe la rutina impuesta por el establecimiento educacional y el monitoreo de los niños por parte de los docentes se hace más difícil, ${ }^{16}$ el rol de los padres y apoderados se vuelve fundamental. Para el aprendizaje a distancia no solo es importante contar con la ayuda de un adulto en el hogar, especialmente para los niños más pequeños, sino que también su capital cultural juega un rol crucial. En general, los apoderados reportan ayudar a sus hijos en sus actividades escolares como tareas y a estudiar para las pruebas, sobre todo en la Enseñanza Básica. ${ }^{17}$ Pero la eficacia con que puedan hacerlo dependerá de su nivel de conocimiento, lo que se asocia fuertemente con su nivel de educación. Si bien en la educación chilena se evidencia una asociación entre el nivel de desempeño de los estudiantes con el nivel educacional de los padres, uno de los objetivos centrales de la política pública es romper esta relación e igualar las oportunidades a través de la enseñanza escolar de calidad. Sin duda, aún queda mucho camino por recorrer, pero al respecto existen experiencias exitosas en contextos vulnerables y muchos establecimientos se esfuerzan por compensar las carencias de sus estudiantes. Lo anterior también se observa en el Gráfico 9, que muestra la distribución de los estudiantes en función de los estándares de aprendizaje del SIMCE 2018, según el nivel de educación de los padres. Si bien en este gráfico se constata que los escolares

\footnotetext{
${ }^{16}$ Según "La mirada de los docentes" (2020), el 62\% de los docentes encuestados dice tener contacto con sus estudiantes frecuentemente, pero en promedio solo se han logrado comunicar con la mitad de ellos. Los medios de comunicación más usados son internet $(50 \%)$ y teléfono $(42 \%)$.

17 Según los resultados del cuestionario realizado a los apoderados del SIMCE 2018, solo el $6 \%$ de los apoderados de cuarto básico y el 13\% de los de sexto básico declaran no ayudar nunca o casi nunca en las actividades escolares de sus hijos, como tareas, y a estudiar para pruebas. Esta proporción aumenta al $40 \%$ entre los apoderados de estudiantes de segundo medio. En todos los grados se evidencia una mayor diferencia de acuerdo a la dependencia administrativa más que debida al nivel educacional de los padres. En particular, esta proporción es mayor entre los apoderados de establecimientos municipales y particulares subvencionados que entre los de establecimientos particulares pagados.
} 
cuyos padres tienen menos años de educación se concentran en el nivel de desempeño insuficiente, el 28\% logra un buen desempeño en cuarto básico, proporción que disminuye dramáticamente en los niveles superiores, en los cuales parecería que pesan más la educación de los padres.

Gráfico 9. DISTRIBUCIÓN DE ESTUDIANTES POR ESTÁNDAR DE APRENDIZAJE EN LECTURA (SIMCE 2018), SEGÚN NIVEL DE ENSEÑANZA Y NIVEL DE EDUCACIÓN DE LOS PADRES

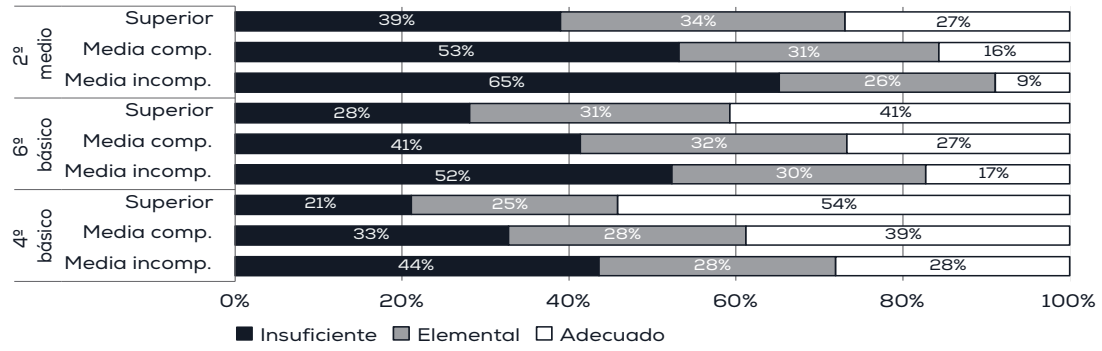

Fuente: Elaboración propia en base a los datos de la Agencia de Calidad de la Educación (2020a).

En tiempos en que la interacción con los profesores disminuye fuertemente y el apoyo escolar recae en gran medida en los padres $\mathrm{u}$ otros adultos en el hogar, es probable que el aprendizaje de los escolares dependa aún más de la educación de estos y se acentúe la dificultad que enfrentan los establecimientos en suplir las carencias del hogar. Según la encuesta CASEN 2017, el 40\% de los escolares vive en hogares cuyo jefe de hogar no cuenta con educación media completa. La distribución de la educación del jefe de hogar es muy desigual en función del nivel socioeconómico de la familia. Mientras el 57\% de los escolares del primer quintil de ingresos vive en hogares cuyo jefe de hogar no tiene Enseñanza Media completa, solo el 5\% de los escolares del quintil de mayores ingresos se encuentra en esa situación.

Ahora bien, si consideramos a todos los adultos de la vivienda, solo el $16 \%$ de los niños en edad escolar no cuenta en su vivienda con al menos un adulto con Enseñanza Media completa. Sin embargo, entre los escolares del quintil de menores ingresos este porcentaje aumenta a $29 \%$. La proporción de escolares en los que el máximo nivel alcanzado por los adultos en la vivienda es el de Enseñanza Media completa es de $38 \%$, porcentaje que también varía según el quintil de ingresos. Mientras 
el $85 \%$ de los escolares del quintil de mayores ingresos cuenta con al menos un adulto en su vivienda con educación superior completa - ya sea técnica o universitaria-, solo el $10 \%$ de los escolares de menores ingresos se encuentra en esa situación.

Gráfico 10. DISTRIBUCIÓN DE LOS ESTUDIANTES POR NIVEL EDUCACIONAL DE LOS ADULTOS DE SU VIVIENDA, SEGÚN QUINTIL DE INGRESOS Y TOTAL NACIONAL

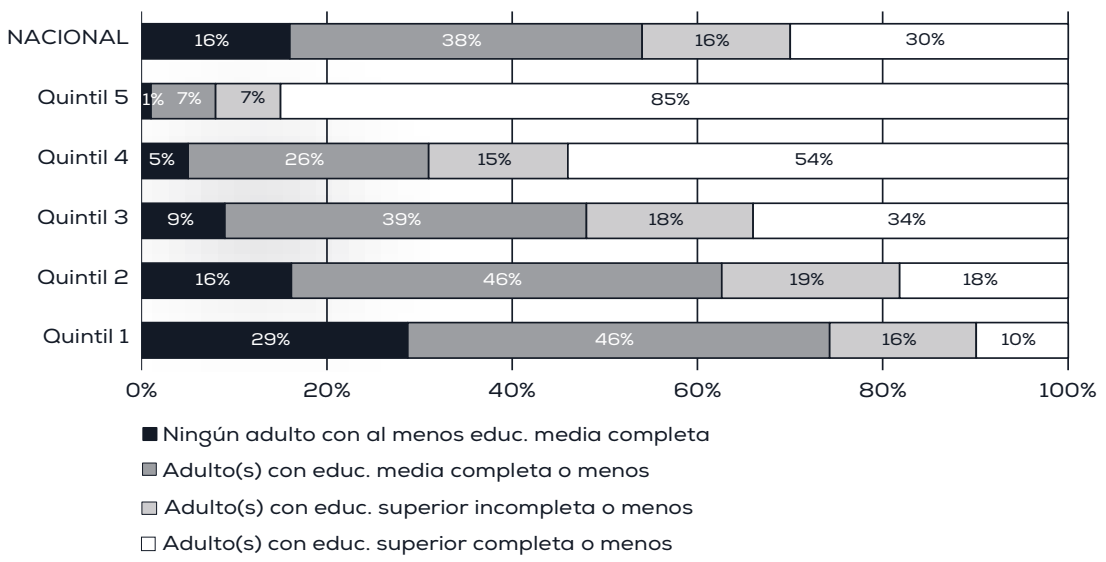

Fuente: Elaboración propia en base a CASEN 2017.

Nota: A excepción del porcentaje de escolares del quintil 5 en viviendas sin adultos con al menos Educación Media completa, todas las estimaciones cumplen (y exceden) los criterios de número de casos y coeficiente de variación recomendados por el MDSF (2018). Para ese grupo, que se estima en $1 \%$ del quintil 5 , son menos de 100 casos no ponderados y el coeficiente de variación es mayor a 0,15 .

Un segundo elemento fundamental es la disponibilidad de los adultos al interior del hogar para que efectivamente puedan apoyar a los niños en su estudio, así como asegurar que los escolares dediquen tiempo al estudio, condición necesaria para el aprendizaje. Entre más adultos por niño, más posibilidades de que los niños reciban el apoyo necesario en el hogar. Según CASEN 2017, el promedio de adultos residentes en viviendas con menores de 18 años es de $2,6^{18}$ y en el $85 \%$ de las viviendas con escolares hay al menos un adulto por cada niño. De estas

\footnotetext{
${ }^{18}$ Según CASEN 2017, el 12\% de los hogares donde viven menores de 18 años habita una vivienda con más de un hogar en ella. Entre los hogares que comparten vivienda, solo el $6 \%$ declara hacerlo para cuidar niños, enfermos o personas con discapacidad. En este artículo se analiza la disponibilidad de los adultos a nivel de vivienda.
} 
viviendas (con al menos un adulto por cada niño), el 5\% tiene al menos un adulto con mucha dificultad o imposibilidad de concentrarse, recordar o comunicarse, por lo que difícilmente estos adultos podrán apoyar a los escolares en sus estudios.

El número de adultos por vivienda no garantiza por sí solo la disponibilidad de adultos para el apoyo en el aprendizaje a distancia, pues es importante considerar también la disponibilidad de tiempo de los adultos. Esta disponibilidad depende de la situación laboral, así como de si se encuentran o no estudiando, condiciones que pueden haber variado desde el trabajo de campo de la CASEN a fines de $2017,{ }^{19}$ en especial dada la actual coyuntura en la que tanto el desempleo como la población fuera de la fuerza laboral han aumentado (INE 2020). Sumando a quienes se han acogido a la Ley de Protección al Empleo, ${ }^{20}$ se podría esperar un aumento en el número de adultos disponibles en el hogar. Sin embargo, una proporción importante seguirá buscando trabajo, o bien, se volcará hacia trabajos informales. A lo anterior ha de sumarse una mayor ansiedad y estrés entre los adultos, a causa de la pérdida del empleo en contextos económicos complejos, lo cual atenta contra la posibilidad de un aumento efectivo en la disponibilidad de adultos en el hogar. Por ello, es difícil estimar el efecto de la crisis económica y el confinamiento en la disponibilidad de adultos al interior de la vivienda, y se ha optado por utilizar los datos existentes de la CASEN 2017. Si bien es esperable que existan diferencias respecto de la situación actual, no está clara la dimensión y la magnitud, y los datos permiten dar cuenta de la envergadura del desafío y de cómo la disponibilidad de adultos varía según quintiles de ingreso.

De esta manera, resulta relevante considerar las viviendas en que al menos hay un adulto en el hogar que no se encuentre trabajando en

\footnotetext{
${ }^{19}$ El trabajo de campo fue realizado durante noviembre de 2017 y febrero de 2018. La tasa de desocupación del trimestre octubre-diciembre 2017 era de 6,5\% (INE 2017). Esta ha aumentado sustantivamente, pasando a $8,2 \%$ en el trimestre enero-marzo 2020 y a $11,2 \%$ en el trimestre marzo-mayo (INE 2020) y se espera un aumento aún mayor en los próximos meses (Benítez, Velasco y Vergara 2020; Vergara 2020).

${ }^{20}$ En el marco del Plan de Emergencia implementado por el gobierno de Chile para hacer frente a la crisis del COVID-19, en el cual, a través de diferentes modalidades, se busca la continuidad del contrato laboral.
} 
modalidad de jornada completa. ${ }^{21}$ Según CASEN 2017, el 30\% de los escolares menores de 18 años no cuenta con un adulto disponible durante la jornada laboral diurna. ${ }^{22}$ Este porcentaje subestima a los niños que probablemente no cuentan con el apoyo suficiente de un adulto en el hogar, puesto que incluye dentro de los adultos disponibles tanto a quienes estudian como a quienes no lo hacen. Los primeros, probablemente también tengan altas demandas de tiempo, de manera que su disponibilidad es menos probable. En un extremo, se podría pensar que los mayores de 18 años que se encuentran estudiando en jornada completa, o bien, estudiando y trabajando al mismo tiempo, carecen de tiempo durante la jornada para apoyar a los escolares en el hogar. Si excluimos también a este grupo, la proporción de escolares que pueden tener dificultades para contar con el apoyo de un adulto durante la jornada escolar, aumenta a $36 \%$. Si además no se consideran como disponibles a quienes se encuentran buscando trabajo, ${ }^{23}$ la proporción de escolares que no cuentan con un adulto durante la jornada aumenta a $42 \% .{ }^{24}$

Como se observa en el Gráfico 11, el porcentaje de escolares que vive en viviendas donde no hay ningún adulto disponible durante la jornada laboral, aumenta a medida que aumenta el ingreso. Esto se debe, principalmente, a la mayor tasa de ocupación de jornada completa en los quintiles de mayores ingresos. Mientras solo el 16\% de los escolares

\footnotetext{
${ }^{21}$ Se considera como trabajador de jornada completa a quienes, en CASEN 2017, reportan que trabajan jornada completa o extendida.

${ }^{22}$ Se considera como disponibles a quienes trabajan jornada parcial, están buscando trabajo o se encuentran inactivos. Sin embargo, no se considera como adultos disponibles a quienes presentan mucha dificultad o imposibilidad de concentrarse, recordar o comunicarse.

${ }^{23} \mathrm{Si}$ bien una proporción de quienes buscan y no encuentran empleo termina por dejar de buscar empleo y, por lo tanto, pasan a considerarse inactivos, esta proporción es menor con respecto a quienes continúan buscando, sobre todo durante períodos más cortos. ${ }^{24}$ Es importante notar que la encuesta CASEN 2017 fue realizada durante noviembre de ese año y febrero de 2018 , cuando la tasa de desocupación del trimestre octubrediciembre 2017 era de $6,5 \%$ (INE 2017). Esta ha aumentado sustantivamente, pasando a $8,2 \%$ en el trimestre enero-marzo 2020 (INE 2020) y se espera un aumento aún mayor en los próximos meses (Benítez, Velasco y Vergara 2020; Vergara 2020), por lo que un número importante de los adultos que en ese momento estaba ocupado habrá perdido su trabajo. Esto podría aumentar el número de adultos disponibles en el hogar, sin embargo, la necesidad de buscar otras formas de ingreso, así como la mayor ansiedad y estrés a causa de la pérdida de empleo en contextos económicos complejos, atentan contra esta posibilidad.
} 
del primer quintil vive en un hogar donde todos los adultos trabajan jornada completa o extendida, en el quinto quintil este porcentaje asciende a $52 \%$. Así, mientras el $71 \%$ de los escolares del primer quintil vive con al menos un adulto inactivo o que trabaja jornada parcial y no estudia, solo el 38\% de los escolares del último quintil está en esa situación.

Gráfico 11. DISTRIBUCIÓN DE LOS ESTUDIANTES POR DISPONIBILIDAD DE ADULTOS EN SU VIVIENDA, SEGÚN QUINTIL DE INGRESOS AUTÓNOMOS DEL HOGAR Y TOTAL NACIONAL

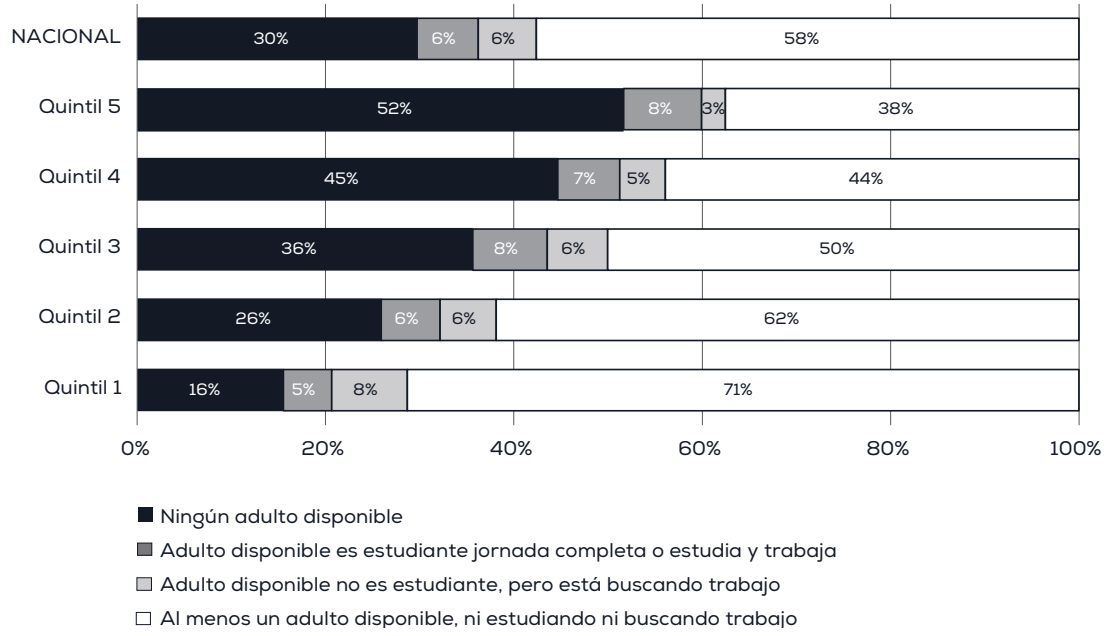

Fuente: Elaboración propia en base a CASEN 2017.

Nota: Solo la proporción estimada de escolares del quintil 5 que cuentan con un adulto disponible, que no es estudiante, pero que está buscando trabajo, no cumple los criterios recomendados por el MDSF (2018).

Considerando el número de adultos con tiempo disponible durante el día (excluyendo solo a quienes trabajan jornada completa) y el nivel de educación de los adultos en la vivienda (Enseñanza Media completa o más), independientemente de si pertenecen al hogar o de si trabajan jornada completa, el $60 \%$ de los escolares vive en hogares donde hay al menos un adulto disponible durante la jornada escolar (ver Gráfico 12). Esta proporción probablemente esté sobreestimada dado que considera como disponibles tanto a quienes estudian jornada completa, estudian y trabajan, como a quienes buscan trabajo. Por otra parte, se considera la presencia de al menos un adulto con Enseñanza Media completa que resida en la misma vivienda que el estudiante, independientemente de si 
pertenece al hogar o no tiene disponibilidad de tiempo. El resto de los escolares debe adecuarse a condiciones menos favorables, que pueden impactar en los logros de aprendizaje.

Como se observa en el Gráfico 12, la proporción de escolares que cuenta con al menos un adulto disponible en la vivienda durante la jornada escolar y con al menos un adulto con Enseñanza Media completa, es menor en el quintil de mayores ingresos $(48 \%)$ y va a aumentando levemente a medida que disminuye el ingreso. Como se advirtió con anterioridad, esto se debe principalmente a que en los quintiles de mayores ingresos hay menos adultos disponibles durante el día, dada la alta proporción de adultos que trabaja jornada completa. Así, 51\% de los escolares del quintil de mayores ingresos vive sin un adulto disponible durante la jornada diurna, versus el $15 \%$ del primer quintil.

Gráfico 12. DISTRIBUCIÓN DE ESCOLARES POR ACCESO A UN ADULTO CON ENSEÑANZA MEDIA COMPLETA Y DISPONIBILIDAD DE AL MENOS UN ADULTO EN LA VIVIENDA DURANTE LA JORNADA ESCOLAR, SEGÚN QUINTIL DE INGRESOS AUTÓNOMOS DEL HOGAR Y TOTAL NACIONAL

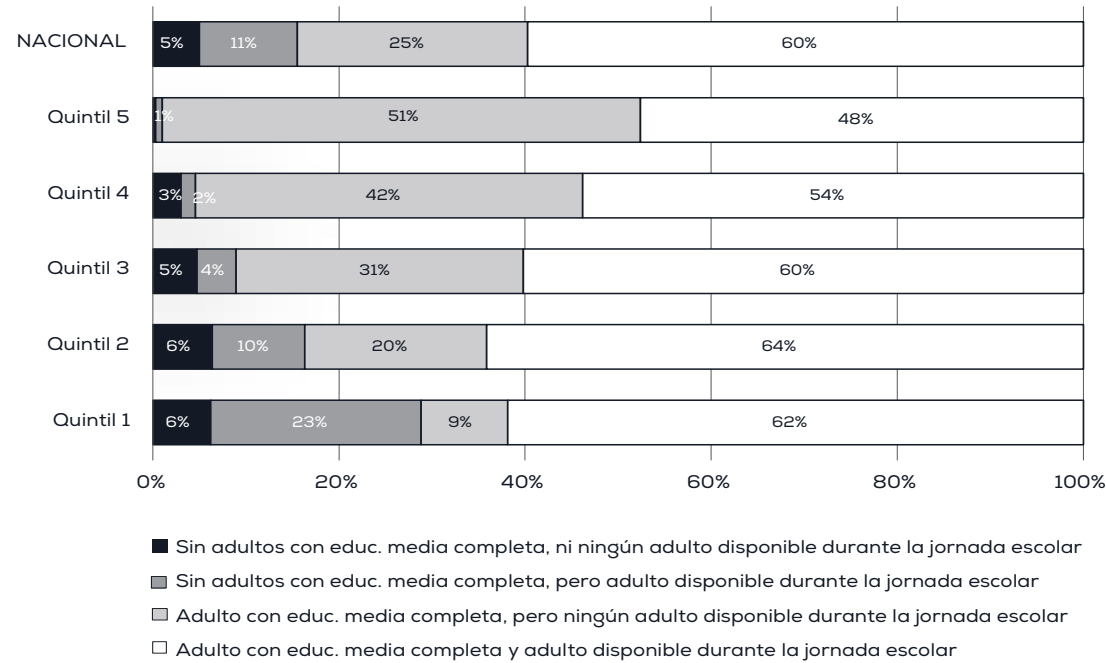

Fuente: Elaboración propia en base a CASEN 2017.

Nota: La proporción de escolares del quintil 5 en los dos primeros grupos (negro y gris oscuro), así como la del segundo grupo del quintil 4 (gris oscuro), no pueden considerarse como confiables según recomendaciones del MDSF (2018): tienen un coeficiente de variación mayor a 0,15 y menos de 100 casos no ponderados. 
La información recopilada nos advierte que cerca del $40 \%$ de los escolares a nivel nacional probablemente no cuenta con el apoyo adecuado de un adulto para el aprendizaje a distancia. El gráfico muestra que en cada quintil de ingresos un porcentaje importante de estudiantes no cuenta con el apoyo adecuado de un adulto, lo que puede repercutir en el aumento de las brechas de aprendizaje al interior de los establecimientos escolares. Ahora bien, no es evidente cómo estas diferencias en el acceso a un adulto con capital cultural impactarán en las brechas por nivel socioeconómico, pues mientras según CASEN 2017 los escolares pertenecientes a las familias del quintil de menores ingresos tienen más disponibilidad de adultos durante la jornada que los escolares del primer quintil, los adultos de estos últimos tienen mayor capital cultural que los adultos disponibles en el primer quintil.

\section{AUMENTO DE LAS BRECHAS EN LOS LOGROS DE APRENDIZAJE DENTRO DEL AULA}

Como se observa en la sección anterior, dentro de un mismo quintil de ingresos hay escolares que cuentan con mejores condiciones para el aprendizaje a distancia que otros. En términos de la disponibilidad de adultos durante la jornada laboral y del capital cultural de los adultos en la vivienda, se observa en todos los quintiles un porcentaje no menor de estudiantes que se encuentra en desventaja. Mientras en el quintil de menores ingresos este porcentaje bordea el $38 \%$, en el quintil de mayores ingresos es de 52\%. Este tipo de diferencias en los apoyos durante el aprendizaje a distancia podría incrementar las diferencias entre alumnos de un mismo curso, que según el estudio de Ramírez (2007) ya eran mayores a las diferencias entre establecimientos antes de la pandemia.

Actualizando el análisis de Ramírez (2007) con datos del SIMCE de Lectura 2018, encontramos resultados similares. Al realizar un análisis de varianza unifactorial (Anova), cuyos resultados se ajustan para tomar en cuenta la estructura jerárquica de los datos (desde regiones hasta cursos dentro de un establecimiento), es posible estimar qué proporción de la varianza en los puntajes SIMCE se encuentra entre las unidades (por ejemplo, cursos) y cuánta dentro de las mismas unidades. ${ }^{25}$ Este análisis

\footnotetext{
${ }^{25}$ Se excluyeron del análisis aquellos cursos con menos de diez alumnos. Las tablas con los resultados se encuentran en el Apéndice.
} 
revela, por un lado, que $19 \%$ de la varianza de puntajes en segundo medio se da entre establecimientos dentro de una misma región, provincia y comuna (similar al 21\% reportado por Ramírez 2007). En el caso de cuarto básico, es de $15 \%$. Es decir, una buena parte de las desigualdades en educación se producen entre escuelas de una misma zona geográfica. Por otra parte, al igual que Ramírez (2007) (y con casi 20 años de diferencia en los datos), encontramos que la varianza en el rendimiento de los alumnos es mayor al interior de un curso o de un establecimiento escolar que entre establecimientos. Para segundo medio, la proporción de la varianza total de los puntajes SIMCE 2018, a nivel de estudiante, que explica la varianza al interior del aula, es $72 \%$. Para cuarto básico, esta proporción es incluso mayor (79\%). Este análisis pone en evidencia la alta heterogeneidad de las aulas en nuestro país respecto de los niveles de aprendizaje de los estudiantes.

Es probable que las dispares condiciones del hogar, que se han analizado a lo largo de este artículo, sean uno de los factores que explican esta variabilidad intraescuela y, por tanto, es esperable que esta varianza aumente durante el período de aprendizaje a distancia a causa del mayor tiempo que los alumnos han debido permanecer en sus casas.

Considerando los datos del grupo socioeconómico al que pertenecen los establecimientos escolares que entrega la Agencia de Calidad de la Educación (2020b) y cruzándolos con las categorías de desempeño con las que la misma Agencia clasifica los establecimientos, es posible ver con mayor detalle cómo varía la dispersión en el SIMCE dentro de un mismo curso en función de estos otros indicadores (Tabla 1). Ello nos permite identificar dónde reside el mayor riesgo de que estas brechas intracursos se profundicen.

En todos los grupos socioeconómicos, la dispersión es menor en los establecimientos de mejor desempeño. Comparando entre grupos socioeconómicos, se observa para cuarto básico una menor desviación estándar en el grupo socioeconómico alto en comparación con los otros grupos (SIMCE 2018), mientras que en el SIMCE de Lectura de segundo medio la desviación estándar dentro de cada curso es mayor en los establecimientos de grupos socioeconómicos medio-altos y altos. ${ }^{26}$

\footnotetext{
${ }^{26}$ Se emplean para este análisis las cinco categorías de grupo socioeconómico definidas por la Agencia de Calidad de la Educación (2020b) en base al índice de vulnerabilidad de la JUNAEB, el nivel educativo de los padres y los ingresos de los apoderados.
} 
Tabla 1. DESVIACIONES ESTÁNDAR PROMEDIO POR CURSO, SEGÚN GRUPOS SOCIOECONÓMICOS Y CATEGORÍAS DE DESEMPEÑO DE LOS ESTABLECIMIENTOS

\begin{tabular}{|c|c|c|c|c|c|c|c|}
\hline \multirow[b]{2}{*}{$\begin{array}{c}\text { Grupo } \\
\text { socioeconó- } \\
\text { mico } \\
\text { del estable- } \\
\text { cimiento }\end{array}$} & \multirow[b]{2}{*}{$\begin{array}{l}\text { Nivel de } \\
\text { logros de } \\
\text { aprendizaje } \\
\text { promedio del } \\
\text { curso }\end{array}$} & \multicolumn{3}{|c|}{ Cuarto básico } & \multicolumn{3}{|c|}{ Segundo medio } \\
\hline & & $\begin{array}{l}\text { Desviación } \\
\text { estándar } \\
\text { promedio } \\
\text { por curso }\end{array}$ & $\begin{array}{c}\% \text { de } \\
\text { desviación } \\
\text { estándar } \\
\text { total }\end{array}$ & $\begin{array}{c}\text { Número } \\
\text { de } \\
\text { alumnos }\end{array}$ & $\begin{array}{c}\text { Desviación } \\
\text { estándar } \\
\text { promedio } \\
\text { por curso }\end{array}$ & $\begin{array}{c}\% \text { de } \\
\text { desviación } \\
\text { estándar } \\
\text { total }\end{array}$ & $\begin{array}{l}\text { Número de } \\
\text { alumnos }\end{array}$ \\
\hline \multirow{3}{*}{ Bajo } & Insuficiente & 47,0 & 88 & 5.756 & 40,3 & 82 & 43.008 \\
\hline & Elemental & 48,9 & 92 & 10.092 & 39,6 & 80 & 6.870 \\
\hline & Adecuado & 41,9 & 79 & 1.247 & * & * & * \\
\hline \multirow{3}{*}{ Medio-Bajo } & Insuficiente & 49,2 & 92 & 14.022 & 42,4 & 86 & 42.598 \\
\hline & Elemental & 49,9 & 94 & 52.394 & 40,8 & 83 & 26.274 \\
\hline & Adecuado & 43,6 & 82 & 8.515 & 31,5 & 64 & 440 \\
\hline \multirow{3}{*}{ Medio } & Insuficiente & 51,1 & 96 & 3.782 & 46,2 & 94 & 13.475 \\
\hline & Elemental & 50,1 & 94 & 53.244 & 42,0 & 85 & 29.349 \\
\hline & Adecuado & 43,6 & 82 & 21.359 & 35,8 & 73 & 1.348 \\
\hline \multirow{3}{*}{ Medio-Alto } & Insuficiente & * & * & * & 49,7 & 101 & 2.754 \\
\hline & Elemental & 50,3 & 94 & 13.719 & 42,9 & 87 & 15.666 \\
\hline & Adecuado & 43,8 & 82 & 19.049 & 36,5 & 74 & 1.093 \\
\hline \multirow{3}{*}{ Alto } & Insuficiente & * & * & * & 52,5 & 107 & 1.597 \\
\hline & Elemental & 52,2 & 98 & 2.272 & 44,6 & 91 & 12.080 \\
\hline & Adecuado & 41,9 & 79 & 19.686 & 35,4 & 72 & 3.846 \\
\hline
\end{tabular}

${ }^{*}$ ) No se reportan las estimaciones en las categorias con menos de 100 estudiantes.

Fuente: Elaboración propia en base a SIMCE 2018.

La presencia de desafíos para la educación a distancia no es exclusiva de los hogares de quintiles de menores ingresos o grupos socioeconómicos más bajos, sino que también existen entre los grupos medios y altos. Existe un riesgo importante de que estos se acentúen con la educación a la distancia, considerando las brechas tanto en equipamiento y características de la vivienda de los estudiantes, como en el acceso a adultos durante la jornada escolar. 


\section{GRUPOS DE RIESGO}

Después de haber analizado los factores que más inciden en el aprendizaje a distancia y luego de ver cómo estos se distribuyen de forma desigual entre la población escolar, resulta clave poder identificar a los escolares más afectados por la suspensión de clases presenciales para focalizar en ellos la ayuda del Estado. A continuación se identifican los grupos de estudiantes que presentan los mayores riesgos de rezago en los aprendizajes y de abandonar el sistema escolar.

\section{Grupos con riesgo de rezago en los aprendizajes y aumento de las brechas}

En las secciones anteriores hemos descrito factores que inciden en las oportunidades de aprendizaje a distancia. En base a ellas, identificamos cuatro factores de riesgo asociados a dos dimensiones. En la primera dimensión se ubican aquellos asociados con la infraestructura: las condiciones físicas de la vivienda, considerando tanto el nivel de hacinamiento como el índice global de calidad de la vivienda, y, en segundo lugar, el equipamiento disponible para el aprendizaje a distancia. Una segunda dimensión dice relación con la posibilidad de contar con apoyo de adultos, tanto como con adultos disponibles durante la jornada escolar en la vivienda, como con la presencia en la vivienda de adultos con Enseñanza Media completa, independientemente de si aquellos están trabajando o estudiando. Si consideramos estos cuatro factores, identificaremos cuatro grupos que se diferencian por su nivel de carencias. El grupo de mayor riesgo reúne a los niños y jóvenes que presentan al menos una carencia en cada dimensión. El segundo grupo de riesgo reúne a los niños y jóvenes que cuentan con carencias en vivienda, pero no en cuanto a la posibilidad de apoyo por parte de adultos en el hogar. El tercero presenta carencias asociadas a la posibilidad de apoyo, pero no con respecto a su vivienda. Finalmente, el cuarto grupo no presenta ningún factor de riesgo.

A nivel nacional, uno de cada tres escolares (900 mil escolares) no presenta carencias en las dos dimensiones identificadas. Sin embargo, se evidencian diferencias según nivel de ingresos: mientras en el primer quintil solo un cuarto de los escolares no se encuentra en ningún grupo 
de riesgo, un poco menos de la mitad (43\%) de los escolares del primer quintil se encuentra en esta condición. Por otra parte, cerca de $550 \mathrm{mil}$ escolares (21\%) se encuentra en el grupo de mayor riesgo, pues presenta al menos una carencia en cada dimensión. Como puede observarse en el Gráfico 13, el 30\% de los escolares del primer quintil se ubica en el grupo de mayor riesgo, mientras que solo el $6 \%$ de los escolares del quintil de mayores ingresos presenta esa condición. ${ }^{27}$

Gráfico 13. DISTRIBUCIÓN DE LOS ESCOLARES POR GRUPO DE RIESGO, SEGÚN QUINTIL DE INGRESOS Y TOTAL NACIONAL

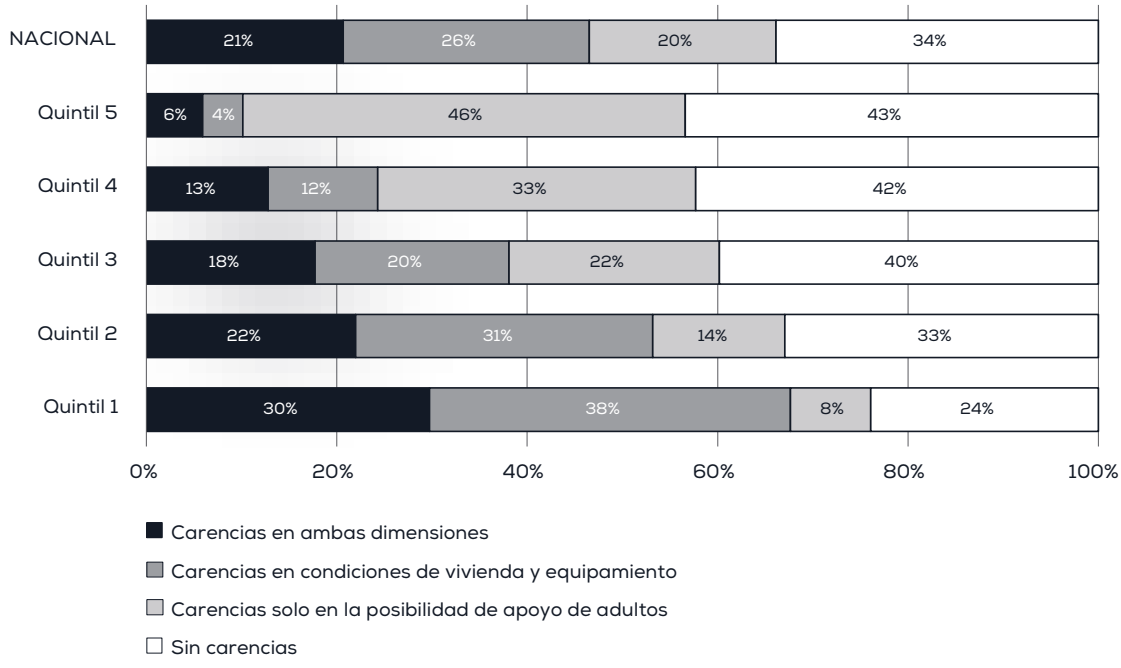

Fuente: Elaboración propia en base a CASEN 2017.

A continuación se analiza cómo se distribuyen los escolares por grupo de riesgo, según zona y región del país. Como se observa en el Gráfico 14, mientras el 36\% de los escolares que vive en zonas rurales se encuentra dentro del grupo de mayor riesgo, solo el $18 \%$ de quienes viven en zonas urbanas se ubica en ese grupo. Ahora bien, dado el bajo volumen de escolares en zonas rurales, el grueso de los alumnos en los grupos de mayor riesgo se encuentra en zonas urbanas.

${ }^{27}$ Los que pertenecen al quintil de mayores ingresos y se encuentran en el grupo de más riesgo son más de 100 casos no ponderados, pero el coeficiente de variación es de 0,17 , de manera que se debe tener cuidado en su interpretación, siguiendo las recomendaciones de MDSF (2018). 
A nivel regional también se observa una distribución desigual de los grupos de riesgo. El Gráfico 15 muestra las regiones que presentan mayor, menor o similar proporción de escolares en el grupo de mayor riesgo en comparación con el promedio nacional. Se advierte que en la mayoría de las regiones del centro-sur y sur de Chile hay una mayor proporción de estudiantes en el grupo de mayor riesgo, así como también en la Región Metropolitana.

Gráfico 14. DISTRIBUCIÓN DE ESCOLARES POR GRUPO DE RIESGO, SEGÚN ZONA Y TOTAL NACIONAL

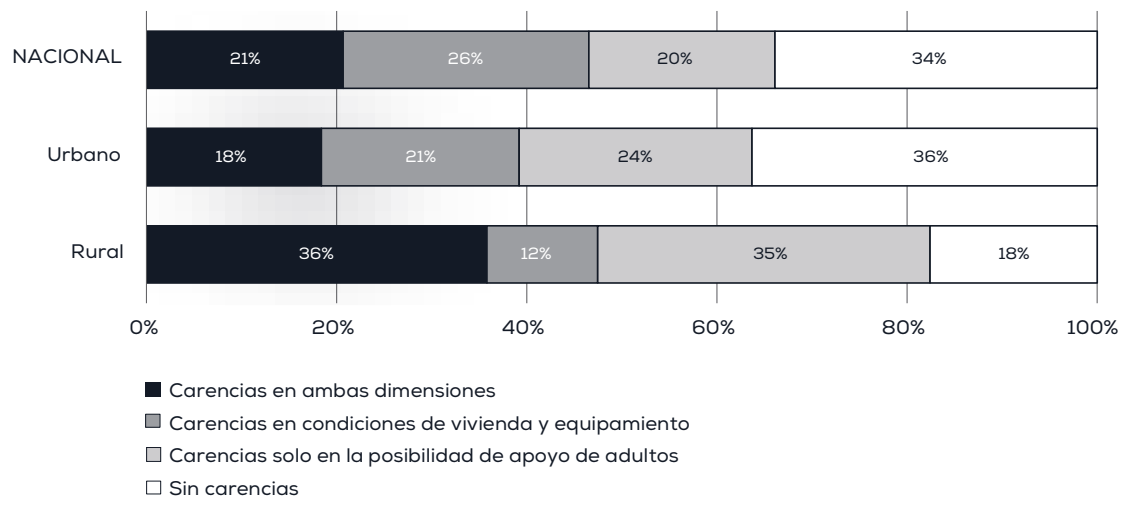

Fuente: Elaboración propia en base a CASEN 2017.

El Gráfico 16 muestra cómo se distribuyen los escolares por grupo de riesgo, en función de la dependencia administrativa de los establecimientos escolares. Se advierte que en los establecimientos financiados por el Estado se concentran los estudiantes de mayor riesgo, con especial énfasis en las escuelas y liceos municipales.

Alta preocupación genera la concentración de escolares que presentan mayor riesgo en los establecimientos de menor desempeño, como muestran los gráficos 17A y 17B. Mientras que un poco más de un cuarto de los escolares de educación básica y media que estudian en establecimientos de categoría de desempeño insuficiente pertenecen al grupo de mayor riesgo, solo el 14\% de los escolares de básica y $10 \%$ de los de media lo presentan. 
Gráfico 15. DIFERENCIA EN LA PROPORCIÓN DE ESCOLARES EN EL GRUPO DE MAYOR RIESGO A NIVEL REGIONAL EN COMPARACIÓN CON EL PROMEDIO NACIONAL*

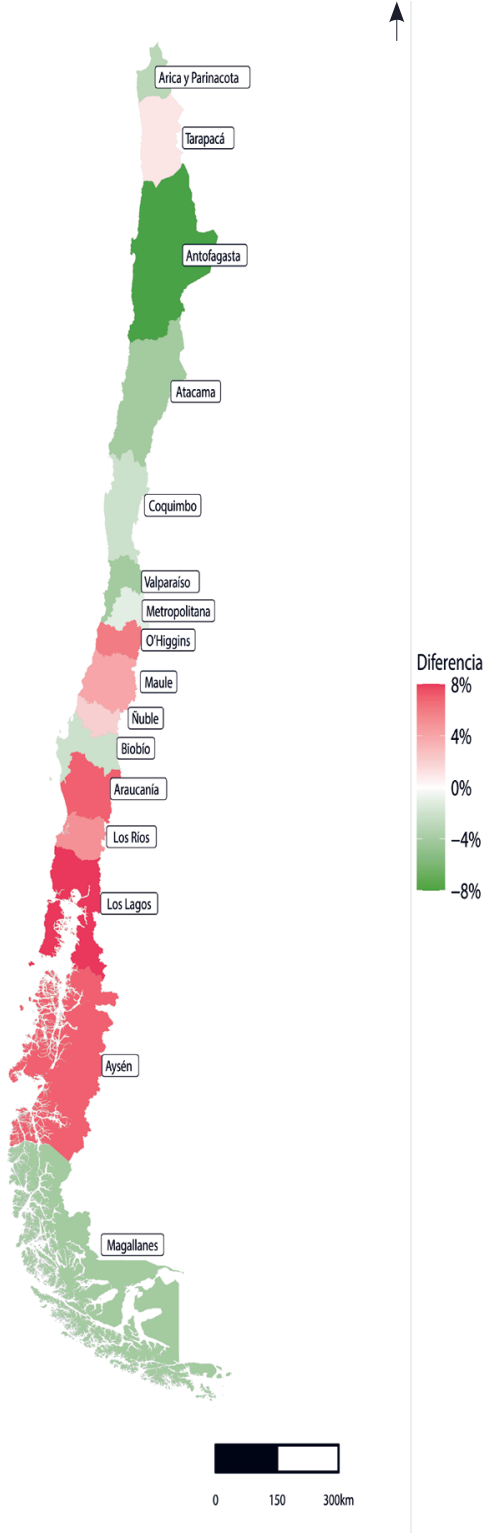

Fuente: Elaboración propia en base a CASEN 2017

* Las autoras agradecen a Clemente Larrain por la colaboración en este gráfico. 
Gráfico 16. ESCOLARES POR GRUPO DE RIESGO, SEGÚN DEPENDENCIA ADMINISTRATIVA DEL ESTABLECIMIENTO Y TOTAL NACIONAL

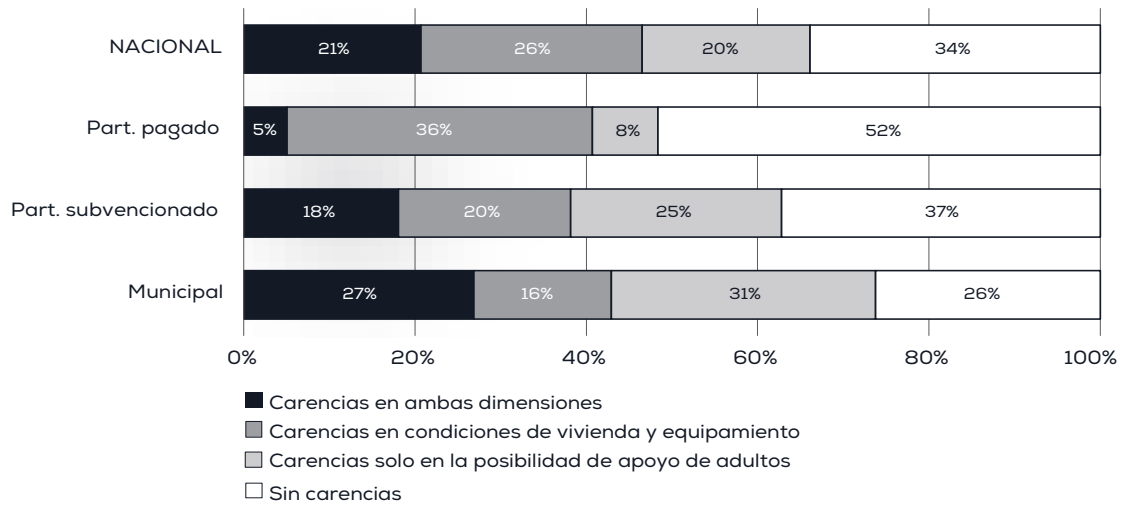

Fuente: Elaboración propia en base a CASEN 2017.

La Tabla 2 caracteriza los cuatro grupos de escolares en función del riesgo que ellos presentan en factores que son clave para alcanzar los estándares de aprendizaje.

El análisis aquí presentado permite identificar factores de riesgo que potencian las brechas de aprendizaje asociadas a las características de la vivienda, acceso a herramientas digitales, disponibilidad de adultos en el hogar y capital cultural de los adultos, así como muestra las características de los establecimientos escolares donde se concentran los niños que presentan los mayores riesgos. Estos factores también inciden en la deserción escolar, que será analizada a continuación.

\section{Grupos de riesgo de deserción escolar}

Otro de los riesgos que advertimos producto de la suspensión de clases presenciales es el aumento de la deserción escolar. Según el Ministerio de Educación, actualmente cerca de 185 mil niños y jóvenes se encuentran excluidos del sistema escolar y este número podría aumentar en $40 \%$ debido a la suspensión de clases presenciales (Bonomelli, Castillo y Croquevielle 2020). La deserción escolar tiene efectos negativos tanto para las personas como para el país. A nivel individual, la deserción impacta negativamente en la inclusión social de las personas, en sus 
Gráfico 17. ESCOLARES POR GRUPO DE RIESGO, SEGÚN CATEGORÍAS DE DESEMPEÑO DEL ESTABLECIMIENTO Y TOTAL NACIONAL*

\section{A: Enseñanza Básica}

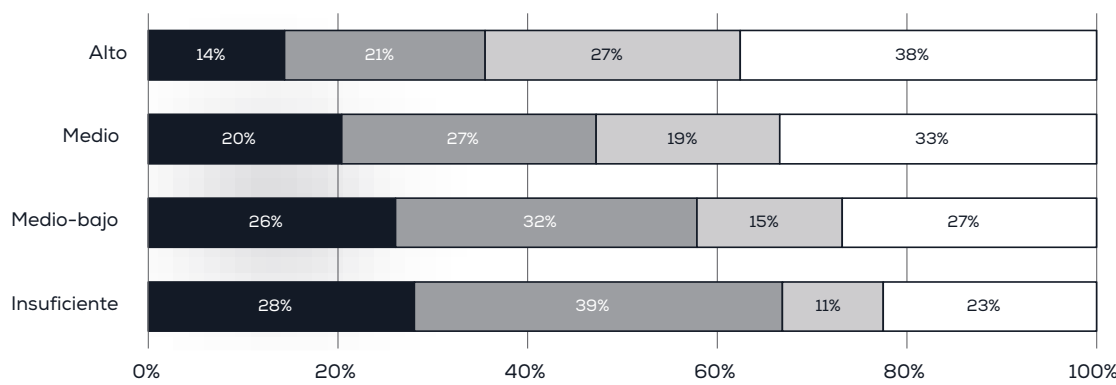

Carencias en ambas dimensiones

$\square$ Carencias en condiciones de vivienda y equipamiento

$\square$ Carencias solo en la posibilidad de apoyo de adultos

$\square$ Sin carencias

17B: Enseñanza Media

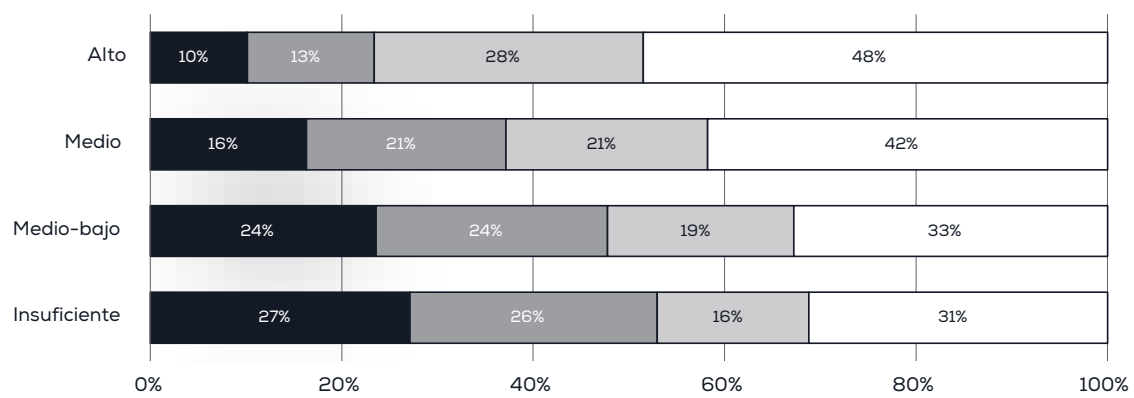

Carencias en ambas dimensiones

$\square$ Carencias en condiciones de vivienda y equipamiento

$\square$ Carencias solo en la posibilidad de apoyo de adultos

$\square$ Sin carencias

Fuente: Elaboración propia en base a CASEN 2017 y Categorias de Desempeño 2017, en Agencia de Calidad de la Educación (2020a).

* Las autoras agradecen a Francisco Cortés por su riguroso trabajo como ayudante de investigación para esta sección. 
Tabla 2. CARACTERIZACIÓN DE LOS GRUPOS DE RIESGO

\begin{tabular}{|c|c|c|c|}
\hline & \multicolumn{2}{|c|}{ Dimensión de apoyo de adultos } \\
\hline & & Con riesgo & Sin riesgo \\
\hline \multirow{2}{*}{$\begin{array}{l}\text { Dimensión } \\
\text { de vivienda } \\
\text { y equi- } \\
\text { pamiento } \\
\text { fisico }\end{array}$} & Con riesgo & $\begin{array}{l}\text { Grupo } 1 \\
\text { Riesgo alto ( } 21 \% \text { a nivel nacional) } \\
\text { Presenta }>1 \text { carencia en ambas di- } \\
\text { mensiones: } \\
42 \% \text { pertenece al primer quintil, } \\
\text { solo } 3 \% \text { al quinto quintil. } \\
33 \% \text { se encuentra en zonas rura- } \\
\text { les. } \\
\text { Enseñanza Básica: } 10 \% \text { estudia en } \\
\text { establecimientos en categoría de } \\
\text { desempeño insuficiente y } 13 \% \text { en } \\
\text { categoria de desempeño alto. } \\
\text { Enseñanza Media: } 16 \% \text { estudia en } \\
\text { establecimientos en categoria de } \\
\text { desempeño insuficiente y solo } 10 \% \\
\text { en categoría de desempeño alto. }\end{array}$ & $\begin{array}{l}\text { Grupo } 2 \\
\text { Riesgo en dimensión de vivienda ( } 26 \% \\
\text { a nivel nacional) } \\
\text { Presenta carencia de equipamiento } \\
\text { disponible o hacinamiento en su hogar: } \\
43 \% \text { de este grupo pertenece al pri- } \\
\text { mer quintil y solo } 2 \% \text { al de mayores } \\
\text { ingresos. } \\
18 \% \text { se encuentra en zonas rurales. } \\
\text { Enseñanza Básica: } 10 \% \text { estudia en } \\
\text { establecimientos en categoria de des- } \\
\text { empeño insuficiente y } 14 \% \text { en categoria } \\
\text { de desempeño alto. } \\
\text { Enseñanza Media: } 13 \% \text { estudia en es- } \\
\text { tablecimientos en categoria de des- } \\
\text { empeño insuficiente y } 11 \% \text { en categoria } \\
\text { de desempeño alto. }\end{array}$ \\
\hline & Sin riesgo & $\begin{array}{l}\text { Grupo } 3 \\
\text { Riesgo en dimensión de apoyo } \\
\text { (20\% a nivel nacional) } \\
\text { Carece de presencia de adultos } \\
\text { disponibles, o bien, de adultos con } \\
\text { Enseñanza Media completa: } \\
\text { Mayor concentración en quintiles } \\
\text { de altos ingresos: el } 13 \% \text { pertenece } \\
\text { al primer quintil y el } 22 \% \text { al quinto } \\
\text { quintil. } \\
8 \% \text { se encuentra en zonas rurales. } \\
\text { Enseñanza Básica: } 4 \% \text { estudia en } \\
\text { establecimientos en categoría de } \\
\text { desempeño insuficiente y } 26 \% \text { en } \\
\text { categoría de desempeño alto. } \\
\text { Enseñanza Media: } 8 \% \text { estudia en } \\
\text { establecimientos en categoria de } \\
\text { desempeño insuficiente y } 22 \% \text { en } \\
\text { categoria de desempeño alto. }\end{array}$ & $\begin{array}{l}\text { Grupo } 4 \\
\text { Sin factores de riesgo de vivienda ni } \\
\text { apoyo ( } 34 \% \text { a nivel nacional) } \\
21 \% \text { se encuentra en el quinto quintil y } \\
12 \% \text { en el primer quintil. } \\
\text { Sin factores de riesgo de vivienda ni de } \\
\text { apoyo (34\% a nivel nacional) } \\
21 \% \text { se encuentra en el quinto quintil y } \\
12 \% \text { en el primer quintil. } \\
\text { Solo } 7 \% \text { (menor que en otros grupos) } \\
\text { estudia en zonas rurales. } \\
\text { Enseñanza Básica: } 5 \% \text { estudia en esta- } \\
\text { blecimientos en categoria de desem- } \\
\text { peño insuficiente y } 22 \% \text { en categoria } \\
\text { de desempeño alto. } \\
\text { Enseñanza Media: } 8 \% \text { estudia en esta- } \\
\text { blecimientos en categoría de desem- } \\
\text { peño insuficiente y } 21 \% \text { en categoria de } \\
\text { desempeño alto. }\end{array}$ \\
\hline
\end{tabular}


relaciones interpersonales, en su salud física y mental, así como en sus posibilidades laborales. Los jóvenes excluidos del sistema escolar son más proclives al consumo de drogas y a cometer delitos (Vásquez, Ramos y Maravilla 2009; Vaughn et al. 2011), tienen mayores dificultades para insertarse laboralmente $\mathrm{y}$, en promedio, acceden a los trabajos peor remunerados del mercado (European Commission 2013). Además, la deserción escolar afecta la capacidad productiva del país, la cohesión social y el gasto social (Marchbanks et al. 2015; Jiménez 2007; Latif, Choudhary y Hammayun 2014).

Los factores que inciden en la deserción escolar son múltiples. Por una parte, se identifica la dimensión familiar y el entorno del estudiante. La evidencia señala que hogares con carencias económicas, estructuras familiares poco claras, bajo capital cultural de los padres y entornos poco seguros (hacinamiento, violencia, drogas, entre otros) favorecen la deserción escolar de los niños (Beatty et al. 2001; Santos 2008; CortésRojas et al. 2019). Por el contrario, el involucramiento parental en el proceso educativo de los hijos, estrechos lazos vinculares y relaciones de confianza entre hijos y padres son factores que ayudan a la retención escolar (Blondal y Adalbjarnardottir 2014; Peña, Soto y Calderón 2016). También hay factores intraescuela o incluso del sistema educativo general que inciden en la deserción escolar. La literatura señala que el número de alumnos por curso, la concentración de alumnos de bajo rendimiento, la calidad pedagógica de los docentes y las expectativas de estos sobre sus alumnos son factores que inciden en la exclusión escolar (Beatty et al. 2001; Martínez 2015; Claro et al. 2016). En Chile, la estructura del sistema escolar tampoco ayuda a la retención escolar, concentrándose la deserción en los años de transición (séptimo básico y primero medio), que es cuando finaliza la educación básica y los estudiantes deben migrar a los liceos. Otra dimensión tiene relación con características propias del niño. Según Lansford et al. (2016), niños con consumo problemático de alcohol y drogas o que han cometido delitos, tienen una mayor probabilidad de desertar. El embarazo adolescente también es un factor que incide en la deserción escolar. Por una parte, los padres buscan trabajo para poder solventar la subsistencia de su familia y, por otra parte, el cuidado del niño dificulta la inserción escolar de la madre adolescente (Peña, Soto y Calderón 2016). 
La deserción escolar es el desenlace de un largo proceso, de ahí que sea tan difícil revertirlo. La evidencia muestra que es más eficaz prevenir la deserción que lograr la reinserción. Para ello es fundamental hacer un seguimiento a la trayectoria escolar de los estudiantes, considerando en especial las variables que mejor predicen la deserción. La literatura señala que el rezago escolar, el promedio bajo de notas (en particular reprobar matemática y lenguaje), el ausentismo crónico (bajo $80 \%$ de asistencia) y problemas de conducta son indicadores que permiten identificar a los estudiantes con mayor riesgo de desertar (Gleason y Dynarski 2002; Espinoza et al. 2014; Franklin y Trouard 2014; U.S. Department of Education 2016; Smerillo et al. 2018; Neild y Balfanz 2006; Balfanz, Herzog y Mac Ive 2007).

La prolongada suspensión de clases presenciales puede tener un impacto negativo en el proceso de aprendizaje de los estudiantes, pero aún más en quienes ya tenían una trayectoria escolar compleja. Los aumentos en las brechas de aprendizaje entre compañeros, la falta de contacto con el docente y los compañeros debilitan el vínculo del estudiante con la escuela y pueden producir desmotivación por retomar los estudios (Raczynski 2002; Rivas, Beltrán y Salazar 2013). Los alumnos en riesgo de desertar no se distribuyen de forma homogénea entre los distintos niveles de enseñanza y entre los diferentes tipos de establecimientos. Si analizamos a la población escolar respecto de los indicadores que mejor predicen la deserción y para los cuales tenemos datos, advertimos que $4 \%$ y $1 \%$ de los estudiantes tiene uno o dos años de rezago escolar, respectivamente. Estos estudiantes se concentran en establecimientos escolares municipales: mientras el 39\% de los escolares a nivel nacional estudia en un establecimiento municipal, el 55\% de los estudiantes con rezago escolar estudia en ellos. En segundo lugar, se concentran en los establecimientos particulares subvencionados, que presentan el $42 \%$ de los escolares con rezago escolar (ver Gráfico 18A).

En relación con el rendimiento académico, 7\% de los estudiantes tiene un promedio inferior a nota 5 . Este porcentaje también se concentra en el sector subvencionado por el Estado (45\% en establecimientos municipales y $54 \%$ en particulares subvencionados). El nivel de enseñanza con mayor concentración de alumnos con bajo rendimiento académico es primero medio (21\% del total de alumnos de bajo rendimien- 
to) (ver Gráfico 18B). No se advierten diferencias en la distribución de los escolares con rezago escolar y bajo rendimiento académico en función de la zona (rural o urbana).

Finalmente, si analizamos la asistencia escolar, se observa que el $14 \%$ de los escolares tiene una asistencia inferior a $85 \%$, que es el umbral mínimo para ser promovido de grado, y $7 \%$ tiene una asistencia menor a $80 \%$, que es considerado ausentismo crónico. Estos últimos estudiantes se concentran sobre todo en los establecimientos municipales en un porcentaje similar a los estudiantes rezagados $(52 \%$ de los escolares con ausentismo crónico se encuentra matriculado en este tipo de establecimientos y $45 \%$ en particulares subvencionados) (ver Gráfico 18C). El ausentismo es levemente mayor en los establecimientos urbanos, donde llega al 8\%, en comparación con los establecimientos rurales donde el porcentaje de ausentismo es de $5 \%$.

Rendimiento, ausentismo crónico y rezago no son independientes entre sí y probablemente potencian el riesgo de deserción. Por ello, es importante analizarlos juntos. En 2019, poco más de 50 mil estudiantes $-2 \%$ de la matrícula - presentaban ausentismo crónico junto con bajo rendimiento escolar. De este grupo, el $27 \%$ presenta rezago escolar de al menos un año. Son cerca de 13 mil alumnos y constituyen el grupo que presenta el mayor riesgo de desertar. Estos estudiantes se concentran en la Enseñanza Media (53\%), en establecimientos municipales (67\% en Enseñanza Básica y 59\% en Enseñanza Media), urbanos $(93 \%)$ y en la categoría de desempeño medio-bajo (46\% en la Enseñanza Media). En cuanto a la distribución por regiones, ninguna región tiene más o menos de 0,3 puntos porcentuales de diferencia respecto del promedio nacional y, por ende, los estudiantes se concentran en las regiones más populosas (Región Metropolitana, Valparaíso y Bío-Bío). Finalmente, cruzando la información con datos del SIMCE 2017 y $2018,{ }^{28}$ se observa que las familias de bajos ingresos (menores a $\$ 400.000$ mensuales) y en las que ninguno de los padres completó la Enseñanza Media concentran desproporcionadamente a más niños con riesgo de desertar que otro tipo de familias. El 78\% de los escolares con mayor riesgo de deserción estudia en establecimientos cuyo grupo socioeconómico promedio es bajo o medio-bajo.

${ }^{28}$ Este análisis, por lo tanto, solo incluye a quienes rindieron el SIMCE esos años. 
Gráfico 18. DISTRIBUCIÓN DE ESTUDIANTES CON CADA FACTOR DE RIESGO DE DESERCIÓN EN COMPARACIÓN CON EL TOTAL NACIONAL, SEGÚN CATEGORÍA DE DESEMPEÑO, NIVEL Y DEPENDENCIA ADMINISTRATIVA

18A: Distribución de estudiantes con rezago escolar

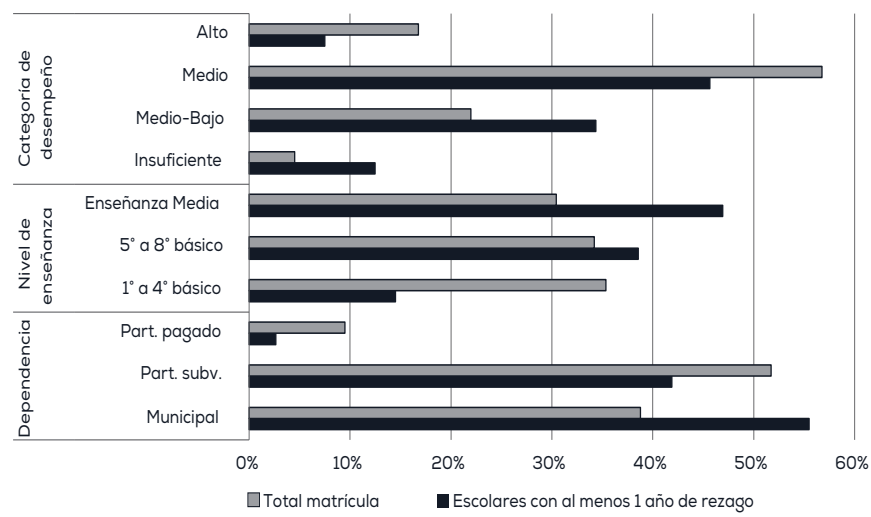

18B: Distribución de estudiantes de bajo rendimiento académico (promedio general bajo 5)

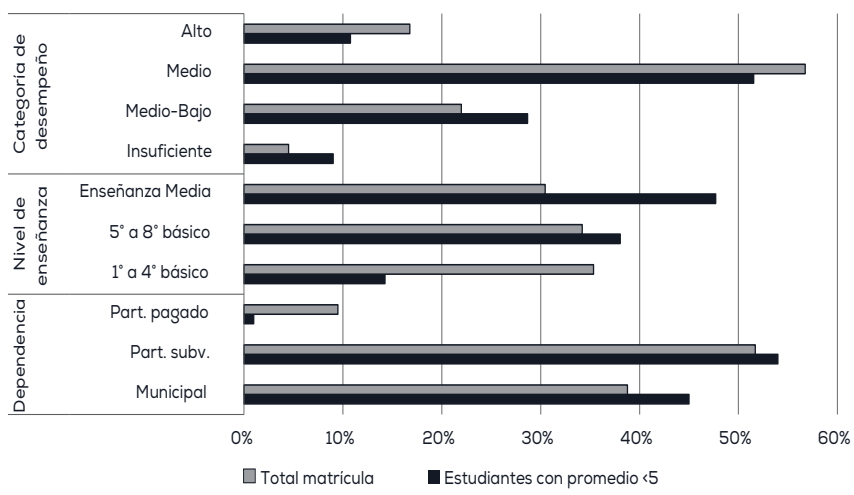

18C: Distribución de estudiantes con ausentismo crónico (asistencia bajo el 80\%)

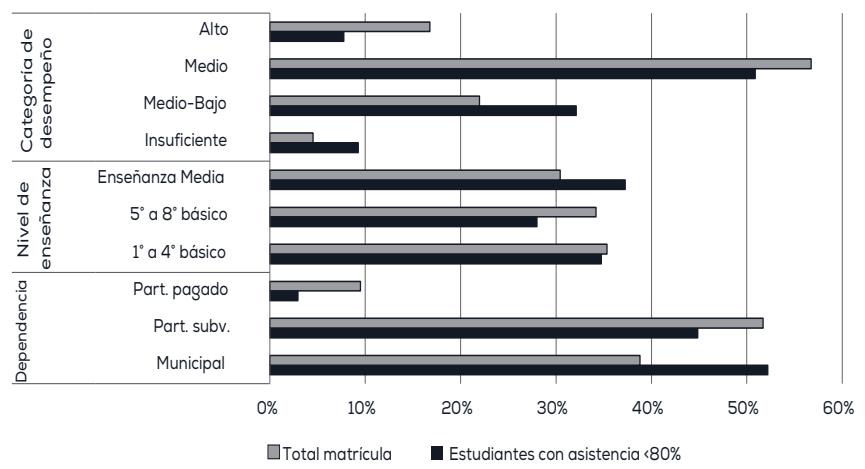

Fuente: Elaboración propia en base a datos de asistencia y rendimiento, Categorías de Desempeño 2019, en Agencia de Calidad de la Educación (2020a). 
Gráfico 19. DISTRIBUCIÓN DE ESTUDIANTES DE ENSEÑANZA MEDIA CON MÚLTIPLES INDICADORES DE RIESGO DE DESERCIÓN ESCOLAR (AUSENTISMO, BAJAS NOTAS Y REZAGO) EN COMPARACIÓN CON EL TOTAL NACIONAL, SEGÚN CATEGORÍA DE DESEMPEÑO Y GRUPO SOCIOECONÓMICO (GSE) DEL ESTABLECIMIENTO, INGRESOS DEL HOGAR Y EDUCACIÓN DE LOS PADRES

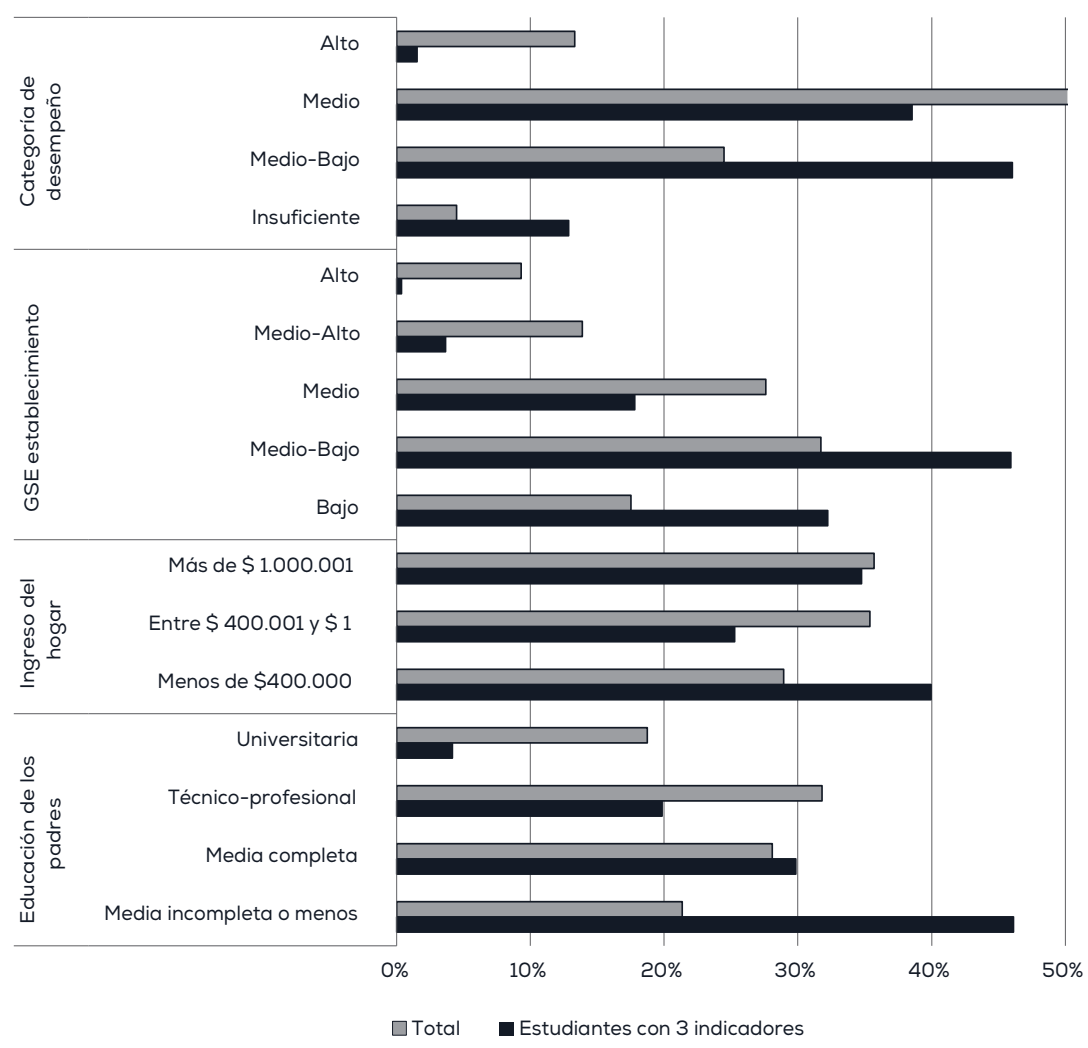

Fuente: Elaboración propia en base a datos de asistencia y rendimiento, Categorías de Desempeño 2019, en Agencia de Calidad de la Educación (2020a), y SIMCE 2017, 2018.

Los análisis anteriores muestran que, previo a la pandemia, cerca de 50 mil escolares presentaban bajo rendimiento académico y ausentismo crónico; de estos, 13 mil tienen rezago escolar de al menos un año. Según la literatura, estos escolares presentan altas probabilidades de desertar del sistema educacional. Sin duda, esta situación se ha agravado desde entonces. De acuerdo a la encuesta "La mirada de los docentes" (2020), más de la mitad de los escolares no ha tenido contacto alguno con sus docentes durante el período de educación a distancia, fragi- 
lizando esto el vínculo de los escolares con su comunidad educativa. Asimismo, la desigual distribución de las habilidades TIC de docentes y estudiantes; de las habilidades de comprensión de lectura; del acceso a internet, a un computador o Tablet; de la calidad de la vivienda o del capital cultural al interior del hogar hacen que el impacto negativo de la suspensión de las clases presenciales sea especialmente crítico en los escolares de menores recursos, con mayores dificultades de aprendizaje y con menor acceso a un adulto durante la jornada escolar; niños y jóvenes que son, precisamente, quienes tienen per se mayor riesgo de desertar del sistema escolar.

\section{RECOMENDACIONES DE POLÍTICA PÚBLICA}

La suspensión de clases presenciales junto con el confinamiento tienen un impacto negativo en distintas dimensiones del bienestar de los niños y jóvenes. Distintos organismos internacionales (UNESCO, OCDE, FAO, BID, Banco Mundial, Brookings Institution, entre otras) han alertado de estos efectos, que hoy están invisibilizados en el debate público nacional. Junto con ello, persiste la incertidumbre respecto de los eventuales beneficios que reporta la suspensión de las clases presenciales en el control de la pandemia.

A diferencia de otras enfermedades, tales como la influenza, existen dudas respecto de si los niños son un vector importante de contagio para el COVID-19. En la revista académica Pediatrics, una de las más prestigiosas a nivel mundial en investigaciones en población infantil, Lee y Raszka (2020) concluyen que los niños no son vectores de contagio para el COVID-19, basándose en cinco estudios sobre su transmisión en la población infantil. Los autores recomiendan, basados en la evidencia disponible, abrir los recintos educativos tomando las medidas sanitarias recomendadas. El estudio de Russell et al. (2020) concluye que no hay evidencia de que el cierre de las escuelas haya contribuido al control de la transmisión del virus. Datos sobre brotes de SARS en China, Hong Kong y Singapur sugieren que el cierre de las escuelas no contribuye al control de la pandemia. Por otra parte, estudios recientes de modelamiento de COVID-19 estiman que el cierre de las escuelas previene entre el $2 \%$ y el $4 \%$ de las muertes, significativamente menos que otras medidas. 
A ello se suma un reporte conjunto de las instituciones de salud de Suecia y Finlandia que concluye que las escuelas no cumplieron un rol relevante en la transmisión de la enfermedad (Public Health Agency of Sweden 2020). En Suecia, un análisis comparado no mostró un mayor riesgo entre educadores con respecto a otras profesiones. Sin embargo, otros países sí han presentado brotes en escuelas. Un estudio reciente en Corea del Sur encuentra una tasa de contagio similar a la de los adultos entre los mayores de 10 años (Park et al. 2020). Si bien la evidencia pareciera ser que los menores presentan una menor tasa de contagio y transmisión (Davies et al. 2020; Torjersen 2020), la discusión sigue abierta. Sobre lo que sí hay consenso es sobre los efectos negativos del cierre de las escuelas y, por ende, sobre lo central de sopesar cuidadosamente los pros y contras de esta decisión.

La primera conclusión de este trabajo es recalcar la importancia que tiene para el bienestar de los niños la pronta apertura de los establecimientos escolares, por supuesto en la medida en que las condiciones sanitarias lo permitan. Este retorno será políticamente difícil si el gobierno, la sociedad civil y los medios de comunicación no hacen un esfuerzo por visibilizar el costo que está teniendo la suspensión de las clases presenciales para la población infantil. Sobre todo, se debe hacer un esfuerzo en comunicación hacia los apoderados que presente de forma clara los riesgos y beneficios asociados, así como las medidas implementadas para acotar los riesgos de contagio. El gobierno anunció el retorno a clases para el 1 de julio en Isla de Pascua, así como la segunda semana de julio para las escuelas rurales en las regiones de Aysén y Los Ríos, y se prevé en el corto plazo el retorno en otros lugares del país, donde el contagio es nulo o extremadamente bajo.

Considerando las recomendaciones de distintas organizaciones internacionales, así como las especificidades de nuestro sistema escolar, se proponen a continuación medidas que consideramos fundamentales para el proceso de retorno a las clases presenciales. Además, considerando que el retorno a clases presenciales no será posible en el corto plazo en todo el territorio nacional o para el total de los escolares, este trabajo también incluye recomendaciones para disminuir los riesgos de deserción y de aumentos en la brecha de aprendizaje durante el período de clases a distancia. La mayoría de las recomendaciones corresponden a medidas que debiese implementar el Ministerio de Educación y otras que debiesen tomarse en conjunto con la Agencia de Calidad o en 
coordinación con otros ministerios. Las organizaciones internacionales, así como la evidencia comparada, también delinean diferentes acciones que deben realizar los sostenedores, directores de establecimientos y equipos docentes. Estas medidas sin duda requerirán de coordinación y esfuerzos adicionales a los ya realizados, por lo que además se deben considerar alternativas de financiamiento adicional, así como medidas creativas para allegar más personas durante este período de transición. En este documento incluimos algunas medidas que están relacionadas con las recomendaciones para el Mineduc (OCDE 2020a).

\section{Recomendaciones para un retorno seguro}

Los análisis anteriores visibilizan los riesgos que conlleva la suspensión de las clases escolares presenciales para la población infanto-juvenil. De ahí la necesidad de proponer como primera medida el pronto retorno a las clases presenciales. Sin embargo, para ello se requiere adoptar una serie de medidas que permitan un retorno seguro. A continuación, se recomiendan una serie de medidas, cuya implementación depende del Ministerio de Educación (OCDE 2016, 2020a, 2020b, 2020c; UNESCO 2020a; Giannini, Jenkins y Saavedra 2020; Bos, Minoja y Dalaison 2020; Reimers y Schleicher 2020):

a. Un plan de retorno flexible y dinámico: flexible, porque es poco probable que el retorno a las clases presenciales sea igual para todos. Los pueblos o ciudades que no presenten contagios deberían ser los primeros en retornar a las clases presenciales, resguardando las medidas sanitarias que determine el Ministerio de Salud. Además, es probable que se inicie el retorno a clases en la población infantil que sea menos susceptible de contagio o en la que será más afectada por el aprendizaje a distancia. Es esencial también entregar a los establecimientos flexibilidad para organizar los cursos y horarios de sus clases para permitirles adecuarse de mejor manera dadas sus respectivas realidades. Este retorno será también dinámico, pues de no encontrarse en el corto plazo una vacuna o remedio para el tratamiento del COVID-19, es probable que en los próximos dos años debamos suspender más de una vez las clases presenciales y transitar hacia un modelo dinámico de clases presenciales en combinación con clases a distancia. 
b. Reforzar e implementar junto con el Ministerio de Salud y las comunidades educativas protocolos de sanitización, higiene, distanciamiento social y prevención, que permitan reducir al mínimo la posibilidad de contagio al interior de los establecimientos escolares. Resulta crucial acompañar esta medida con apoyo en el financiamiento de los suministros necesarios para una efectiva implementación de los protocolos. Para un apoyo eficaz se requiere contar con una estimación realista de los costos, así como identificar los mecanismos para solventarlos. De esta forma, se deben identificar y cuantificar los insumos requeridos en función de las características del establecimiento y estudiantado. Se debe también realizar un monitoreo permanente de los protocolos y su implementación para su perfeccionamiento continuo.

c. Flexibilizar los planes de estudios, la jornada y el calendario escolar para que cada comunidad educativa pueda encontrar la mejor forma de resguardar la salud de su comunidad escolar, así como el desarrollo de sus estudiantes durante el proceso de transición. Durante este tiempo, muchos establecimientos deberán reducir el número de estudiantes por aula. Existen diferentes mecanismos que podrían usarse para resolverlo, tales como la creación de dos turnos en el día, alternando días o semanas, extendiendo el calendario de clases o intercalando semanas lectivas con no lectivas, etc. Todo ello dependerá de la disponibilidad de la planta docente, así como - en caso de que sea necesario - adecuar los contratos a las nuevas condiciones.

Los sostenedores, equipos directivos y docentes juegan también un rol fundamental. Por ello, sugerimos:

a. Preparar a la comunidad educativa antes del retorno a clases, sociabilizando los protocolos sanitarios.

b. Implementar y fiscalizar rigurosamente el cumplimiento de dichos protocolos.

\section{Recomendaciones para potenciar el aprendizaje}

Para enfrentar los desafíos tanto del aprendizaje a distancia como durante el retorno a clases presenciales, se recomienda que el Ministerio de Educación adopte las siguientes medidas: 
a. Flexibilidad para la aplicación del currículo y logros de aprendizaje, de manera que las comunidades educativas puedan adaptarlos para potenciar la motivación de los escolares. La motivación siempre debería jugar un papel importante en el proceso de aprendizaje y desarrollo; sin embargo, en el aprendizaje a distancia es indispensable. Ella exige mayor flexibilidad y creatividad para lograr en los estudiantes la motivación interna que permite un estudio más autónomo. Para ello, los docentes deben innovar constantemente y usar la creatividad para encontrar nuevas formas de trabajar los contenidos y desarrollar las habilidades que resulten atractivas para sus estudiantes. La innovación y la creatividad exigen un trato más flexible con el currículo y los logros de aprendizaje definidos por el Ministerio de Educación y el Consejo Nacional de Educación. En esta línea, se recomienda al Mineduc no solo permitir un trabajo absolutamente flexible a las comunidades escolares, sino también transmitir confianza a los sostenedores y docentes para que efectivamente puedan llevar adelante su tarea con la mayor flexibilidad posible. Esto puede, por ejemplo, significar concentrarse en aquellas dimensiones del aprendizaje que son más fáciles de trabajar a distancia, como la lectura, la escritura, el pensamiento crítico, el desarrollo de habilidades de investigación académica, el arte, entre otros. Así también puede significar priorizar aquellos contenidos que sean más significativos para los escolares de esa comunidad en particular, los que pueden variar según las respectivas características.

b. Flexibilizar el sistema de calificación y de promoción. Entregar libertad a las comunidades educativas para que puedan tomar la mejor decisión respecto de su propia realidad, permitiendo la promoción automática para quienes prefieran esa opción y flexibilizando la calificación para que pueda optarse por distintas alternativas de calificación.

c. Adecuación curricular y programas de estudio. El Mineduc elaboró una propuesta de currículo reducido, que fue aprobada recientemente por el Consejo Nacional de Educación. Esta focalización del currículo es fundamental, pues entrega una guía a los docentes sobre los conocimientos y habilidades a priorizar. Sin embargo, ello no es suficiente. La gran mayoría de los docentes trabaja con textos escolares o con los programas de estudio que elabora el 
Mineduc, que no han sido ajustados al nuevo currículo reducido ni al aprendizaje a distancia. Se valora la incorporación de la priorización de los contenidos curriculares en la plataforma "Aprendo en línea", tanto para docentes como para estudiantes. Creemos que es fundamental continuar con este esfuerzo e incorporar o adaptar las actividades para que sean apropiadas para la enseñanza a distancia (más en el punto siguiente). Los programas que desarrollan los propios colegios también pueden servir de insumo para otros establecimientos que no cuentan con las capacidades para desarrollar sus propios programas o para perfeccionarlos. Por ello, es importante implementar el Banco de Programas.

d. Recursos educativos digitales: es fundamental fortalecer y apoyar el trabajo pedagógico de los docentes con sus estudiantes. A este respecto proponemos que el Mineduc, a través del Centro de Perfeccionamiento, Experimentación e Investigaciones Pedagógicas (CPEIP), incorpore nuevas actividades, así como una selección de recursos educativos de calidad no solo ajustados al currículo reducido, sino también adecuados para el aprendizaje a distancia. Estos contenidos podrían ser generados por el propio CPEIP, o bien, seleccionados de otras fuentes (debidamente acreditadas). Los recursos educativos podrían comprender clases grabadas sobre temas específicos anclados al Currículo Nacional, documentales, biblioteca virtual, guía de actividades pedagógicas apropiadas para el trabajo a distancia, programas de matemática o que enseñan a leer, entre otros. En esta línea, se recomienda encontrar un sano equilibrio entre los distintos objetivos de aprendizaje del currículo, priorizar aquellos aprendizajes y habilidades que son más fáciles de adquirir a distancia (música, arte, escritura, comprensión lectora, pensamiento crítico, programación computacional) y utilizar metodologías de aprendizaje que resulten atractivas para los estudiantes, por ejemplo: vincular los aprendizajes con situaciones de la vida real, fomentar la exploración personal a partir de las motivaciones intrínsecas de los estudiantes, llevar adelante proyectos personales o en grupo como una bitácora, por mencionar algunas.

e. Capacitación y acompañamiento: se recomienda al Ministerio de Educación prestar apoyo y capacitación a distancia a los docentes a través del CPEIP y de los Departamentos Provinciales de 
Educación. El desafío de adecuar las clases para el aprendizaje a distancia, así como de incorporar las tecnologías de la información a la educación escolar, es enorme. Junto con ello, una proporción importante de docentes enfrenta la enseñanza a distancia de sus propios hijos u otros menores a su cargo, además de otras situaciones complejas. Por ello, creemos importante un esfuerzo adicional en proporcionar los recursos de planificación, pautas de corrección de las actividades propuestas y otros que alivien la carga y permitan a los docentes concentrarse en la enseñanza y retroalimentación de sus alumnos. La capacitación a distancia debiera ser asincrónica y estar enfocada en los principales desafíos que enfrentan hoy los docentes: didáctica en la enseñanza a distancia, habilidades TIC y entregar apoyo emocional a sus estudiantes.

f. Implementar una red de tutores para apoyar en forma extraordinaria la enseñanza a distancia, con especial foco en estudiantes de mayor riesgo y mayores carencias. Pero también, y en función de los riesgos identificados respecto de la disponibilidad y el capital cultural de los adultos de la vivienda, conformar una línea de resolución de dudas ya sea en forma telefónica o en línea. Esta red de tutores debería estar organizada por la Dirección General de Educación (DEG), en alianza con las escuelas de pedagogía del país para incorporar a estudiantes de pedagogía y recién egresados de dicha carrera. Además, se puede evaluar la incorporación de profesores jubilados a la red de tutores. Se propone mantener esta red durante el período de transición del retorno a clases presenciales como soporte para los docentes de aula, ya sea apoyando a los estudiantes más rezagados, apoyando a todos los escolares para que el profesor pueda asistir mejor a los alumnos con mayor rezago o para trabajar a distancia con los niños y jóvenes que no han retornado a las clases presenciales.

g. Trabajar en un plan de corto plazo que permita reducir las desigualdades en acceso a tecnología, el medio que facilita el aprendizaje a distancia. En concreto, se recomienda que el Mineduc, en conjunto con el Ministerio de Telecomunicaciones y Transporte, identifique las zonas del país habitadas sin acceso a internet y a los estudiantes que no cuentan con herramientas digitales (ni siquiera un smartphone) para desarrollar un plan estratégico que permita 
disminuir las brechas en conectividad, o bien, desarrollar alternativas no digitales. Con respecto a la conectividad, una solución para mejorar el acceso a internet en sectores rurales y de baja conectividad es el sistema de interoperabilidad mundial para el acceso por microondas (WiMax). Se trata de un método de transmisión de datos a través de ondas de radio, que utiliza las frecuencias 2,5 a 5,8 $\mathrm{GHz}$. Es una tecnología que permite llevar internet con un alcance que puede llegar a los $70 \mathrm{~km}$ sin necesidad de cable.

En el artículo identificamos riesgos no solo de brechas entre establecimientos, sino también dentro del aula. Por lo tanto, los docentes deberán enfrentar aulas más diversas respecto de los aprendizajes una vez que vuelvan las clases presenciales. Para poder abordar el desafío de nivelar a los estudiantes y asegurar que todos aprendan, se recomienda al Ministerio de Educación y a la Agencia de la Calidad de Educación:

a. Crear un sistema de evaluaciones diagnósticas voluntarias, que permitan evaluar el desarrollo de las principales habilidades y la adquisición de los conocimientos esenciales para todos los grados con validez a nivel del estudiante. De este modo se podrá facilitar la tarea de los establecimientos y docentes de identificar los principales rezagos y poder tomar las medidas pertinentes.

b. Establecer como obligatorias las evaluaciones diagnósticas para al menos dos grados (cuarto básico y segundo medio), de manera de contar con información censal que permita orientar la política pública y el apoyo del Estado hacia quienes más lo necesitan.

c. Realizar un SIMCE muestral que permita estimar el efecto de la suspensión de clases presenciales en los aprendizajes de los estudiantes. Este SIMCE debe ser comparable con las pruebas de años anteriores. Esto permitiría desarrollar planes de estudio complementarios o especiales para enfrentar el rezago.

d. Además, se sugiere al Ministerio de Educación poner a disposición de los establecimientos educacionales apoyo para el trabajo a distancia con los estudiantes que no han retornado a las clases presenciales a través de la red de tutores, en alianza con las escuelas de pedagogía del país.

Las organizaciones internacionales, así como la evidencia comparada, delinean diferentes acciones que deben realizar los sostenedores, 
directores de establecimientos y equipos docentes. Sin duda, estas medidas requerirán de coordinación y esfuerzos adicionales a los ya realizados, por lo que además se deben considerar alternativas de financiamiento adicional, las recomendaciones anteriores con respecto a flexibilidad, adecuación curricular y apoyos, incluyendo medidas creativas para allegar a más personas durante este período de transición. Dentro de las recomendaciones se encuentran (OCDE 2020a):

a. Durante el aprendizaje a distancia, se sugiere que los sostenedores con el equipo directivo de los establecimientos escolares y con la participación de los docentes generen estrategias para el aprendizaje a distancia sin perder de vista la motivación por aprender, con el objeto de asegurar el desarrollo de todos los estudiantes, considerando las características del territorio y de sus estudiantes. Por ejemplo, en escuelas rurales, donde las familias no gozan de buena conectividad a internet y la razón alumno/docente es baja, la estrategia pedagógica debería basarse principalmente en el material físico que entreguen las escuelas y en la atención personalizada del docente con cada estudiante a través de la señal telefónica, que es la que tiene mayor cobertura. Esta estrategia personalizada es también adecuada para los escolares sin acceso a internet que habitan zonas urbanas, para quienes presentan mayores dificultades en los aprendizajes o que presentan mayor riesgo de desertar. Para las escuelas cuyos niños cuentan con conectividad y disponen de aparatos para conectarse, las clases online son una forma de reducir la distancia. Ahora bien, como vimos anteriormente, la mayoría de los niños no cuenta con un aparato disponible durante las 24 horas. En estos casos, grabar la clase y enviarla por mail o whatsapp puede ser de gran ayuda, así como recurrir a los recursos pedagógicos de calidad que se encuentran disponibles en la web. La retroalimentación de los alumnos puede ser mixta, grupal para quienes puedan conectarse y personalizada para quienes tienen mayores restricciones de comunicación. Estas medidas requieren contar con la flexibilidad en la aplicación del currículo como se señaló anteriormente.

b. El retorno a clases presenciales exige elaborar estrategias de trabajo diferenciado con los estudiantes en función del nivel de logro 
de sus aprendizajes. Además de un aumento de las brechas entre establecimientos, se esperan aumentos de las brechas (de por sí grandes) dentro del aula. Esto requerirá un gran esfuerzo de parte del cuerpo docente y formas innovadores de trabajo en el aula, incluso de la disposición de la jornada escolar. Esto implica al menos identificar a los estudiantes con mayor rezago y elaborar un plan de trabajo con ellos. La reducción de la jornada escolar puede ayudar para destinar más horas a los estudiantes que presentan mayor retraso, mientras que quienes están más adelantados pueden seguir trabajando y profundizando los conocimientos desde el hogar. La implementación de las recomendaciones sobre evaluaciones diagnósticas voluntarias y la generación de recursos apunta a apoyar a los equipos directivos y docentes en esta labor.

\section{Recomendaciones para apoyar el bienestar socioemocional de los estudiantes}

Un motivo de especial preocupación durante la suspensión de clases presenciales y que fue mencionado al inicio de este documento, es el bienestar socioemocional de los estudiantes. Por ello, se recomiendan medidas generales que buscan resguardar el bienestar integral de los niños y jóvenes. La implementación de algunas de estas medidas corresponde al Estado en general, en tanto van más allá de la competencia del Ministerio de Educación (OCDE 2016, 2020a, 2020b, 2020c; UNESCO 2020a; Giannini, Jenkins y Saavedra 2020; Bos, Minoja y Dalaison 2020; Reimers y Schleicher 2020).

a. Continuar asegurando la provisión de alimentación: durante la suspensión de clases presenciales resulta fundamental que el Estado provea de recursos a las familias que más los necesitan para asegurar la alimentación de los niños. A este respecto, la pronta respuesta del Ministerio de Educación para entregar alimentación a los niños que recibían alimentos en los establecimientos educacionales, es acertada y valiosa. Esta política se complementa con las cajas alimenticias que ha distribuido el gobierno a 2,5 millones de hogares y las transferencias directas a las familias más vulnerables para complementar los ingresos y así asegurar recursos que 
permitan sobrellevar esta crisis. Con todo, en la medida en que el confinamiento perdure y se profundice la crisis económica, resulta fundamental evaluar permanentemente que la ayuda del Estado llegue efectivamente a todas a las familias que la necesitan de manera oportuna, especialmente a aquellas que tienen menores de edad (UNESCO 2020b).

b. Desarrollar estrategias para la identificación de niños que han sufrido abusos y entregar herramientas para el apoyo emocional realizado por los equipos docentes: junto con abordar los desafíos más inmediatos de alimentación y recursos necesarios para el bienestar familiar, resulta necesario proveer apoyo emocional a los niños y jóvenes, detectar a quienes están sufriendo abusos y ofrecerles protección durante el período de aprendizaje a distancia. La manera más directa para llegar a ellos es a través de la escuela, dada la alta cobertura escolar que goza Chile, especialmente en la Enseñanza Básica. Para ello se deben intensificar los esfuerzos que hacen las escuelas para contactar a los escolares. Según la encuesta "La mirada de los docentes" (2020), el 62\% de los profesores dice tener una comunicación regular con sus estudiantes, pero en promedio solo logran comunicarse con la mitad de ellos. Esto significa que más de la mitad de los niños y jóvenes no ha tenido contacto con sus respectivos profesores. En esta dimensión, es importante que los docentes reciban apoyo especializado para poder proveer contención emocional adecuada a sus estudiantes y transmitir instrucciones claras de cómo proceder cuando se vean enfrentados a casos de maltrato o abuso. Se recomienda que el Mineduc desarrolle una plataforma en la cual los establecimientos escolares reporten semanalmente la asistencia de los escolares y si los ausentes han podido ser contactados. El Ministerio de Educación, en alianza con el Ministerio de Desarrollo Social y Familia, así como con los municipios, deben generar un plan para contactar a todos los niños y jóvenes que no han podido ser contactados a través de la escuela de forma de asegurarse de su bienestar. Los protocolos para los casos de abusos y maltratos deben ser adecuados para esta nueva realidad, ofreciendo una solución oportuna a los afectados (OCDE 2020a).

c. El Mineduc, a través de la DEG y los Departamentos Provinciales de Educación, debe apoyar a las escuelas para que estas logren 
comunicarse con los escolares que no han podido ser contactados durante las clases a distancia, así como mantener el vínculo a distancia con quienes no hayan retornado una vez que se inicien las clases presenciales. El contacto es fundamental en el período de aprendizaje a distancia, así como durante el retorno a las clases presenciales. Un niño que no ha sido contactado por su profesor durante el período de clases a distancia presenta ceteris paribus no solo mayores probabilidades de desertar que uno que ha sido contactado regularmente, sino también de continuar con su proceso de aprendizaje. El contacto regular con los escolares y sus apoderados debería ser la primera tarea de todo docente y escuela, pues es la condición de posibilidad para el aprendizaje a distancia. Para apoyar a las escuelas en esta tarea resulta fundamental levantar información sobre cuáles son los principales obstáculos y, a continuación, presentar un plan para abordar dichas dificultades y monitorear regularmente dicho contacto.

d. A través del CPEIP, capacitar a los docentes para el apoyo emocional a los escolares para la identificación de situaciones problemáticas y respecto de los protocolos de acción en caso de identificarlos. Es fundamental poder individualizar a quienes han sufrido maltrato, abuso, estrés tóxico o presenten un cuadro depresivo, con el fin de derivarlos oportunamente a profesionales. Por ello, también se recomienda flexibilizar el uso de recursos estatales para, luego del retorno a clases presenciales, permitir la contratación de especialistas que apoyen en la realización de diagnósticos así como en las atenciones derivadas de ese diagnóstico.

\section{Recomendaciones enfocadas en la deserción}

A medida que se extiende el período de suspensión de clases presenciales, aumenta la probabilidad de que niños y jóvenes deserten del sistema escolar y se vuelve más desafiante asegurar que ellos continúen aprendiendo. Para evitar la deserción de la escuela, además de las recomendaciones anteriores que apoyan y motivan el aprendizaje, resulta fundamental establecer contacto regular con todos los alumnos, identificar a quienes presentan mayor riesgo de desertar, así como diseñar estrategias de acompañamiento pedagógico para estos casos. 
Para reducir al mínimo el número de niños y jóvenes que terminen excluidos del sistema escolar, se sugiere:

a. Crear un sistema de alerta temprana: poner en marcha un sistema de alerta temprana que permita identificar a los escolares que presentan mayor probabilidad de desertar. Esta es una tarea conjunta del Mineduc con el MDSF. La evidencia muestra que son múltiples los factores que inciden en la deserción, pero en términos de alerta temprana, la evidencia muestra que los indicadores que mejor predicen la deserción son los que se obtienen de la trayectoria académica del niño y joven (Espinoza et al. 2014). Estos indicadores se pueden enriquecer con información acerca del entorno familiar del estudiante, la que permite identificar mejor a quienes presentan mayores probabilidades de desertar.

b. Estrategias de acompañamiento a escolares con mayor riesgo de desertar: se deben buscar estrategias para profundizar el contacto con los niños y jóvenes que presentan mayores dificultades en el aprendizaje o que muestran mayor riesgo de desertar. Existen experiencias exitosas a nivel nacional e internacional en esta dimensión. Por ejemplo, programas de acompañamiento a distancia para párvulos, en los que los educadores entregan materiales didácticos a las familias y capacitación al cuidador principal para la estimulación temprana de los niños. ${ }^{29}$ Involucrar a las familias en el proceso de aprendizaje de sus hijos es también importante para retener a los escolares en el sistema educativo y lograr que aprendan. De ahí la necesidad de identificar a quienes no cuentan con apoyo en sus hogares para entregarles un respaldo externo. Existen experiencias exitosas de soporte pedagógico a través de tutores que alivian el trabajo de los docentes y suplen, en parte, el apoyo de los apoderados y que pueden prestar ayuda emocional y pedagógica a los estudiantes más necesitados. Los tutores pueden pertenecer al establecimiento educacional (los propios compañe-

\footnotetext{
${ }^{29}$ Por ejemplo, el programa de acompañamiento a párvulos de la organización ParentChild+ en Estados Unidos (ver: https://www.parentchildplus.org). En Chile existen al menos dos fundaciones que entregan este tipo de programas; entre ellas: la Fundación Niños Primero, con su programa Familias Power, y la Fundación CMPC, con su programa Hippy (ver respectivamente: https://www.ninosprimero.cl/programas y https://www. hippychile.cl).
} 
ros de curso, alumnos mayores del mismo colegio o docentes del establecimiento ${ }^{30}$ o pueden ser externos a la institución (alumnos universitarios, docentes externos al establecimiento o plataformas o aplicaciones digitales que entregan apoyo personalizado). En esta línea se recomienda que el Ministerio de Educación, en alianza con las escuelas de pedagogía, cree una red de tutores con los estudiantes de pedagogía. Los tutores deberían trabajar con los docentes de las escuelas, con foco en las escuelas que concentran a los alumnos con mayores riesgos de desertar, ayudando a contactarlos y acompañándolos durante el aprendizaje a distancia.

c. Campaña comunicacional a nivel nacional para promover la retención escolar.

\section{Recomendaciones respecto de financiamiento}

Durante el período de suspensión de clases, así como durante el período de retorno a clases presenciales, los establecimientos necesitan tener certeza acerca del financiamiento que los sustentará.

a. Se sugiere al Ministerio de Educación fijar criterios objetivos y transparentes para el pago de la subvención durante la suspensión de las clases presenciales, así como durante el período de regularización del retorno a clases, el cual no debería considerar la asistencia. Los recursos que reciban los establecimientos deben ser suficientes para asegurar su óptimo funcionamiento. Especialmente preocupante resulta la situación de las escuelas de reingreso, cuya matrícula recién se consolida en abril. Los criterios de pago de la subvención para este tipo de escuelas deberían considerar su especificidad, de lo contrario se corre el riesgo de que cierren.

\footnotetext{
${ }^{30}$ En México, el programa MAPEAL (https://mapeal.cippec.org) ha sido introducido en cientos de escuelas. Este programa de redes de tutoría trabaja con alumnos de la escuela como tutores de sus compañeros. En Singapur y Finlandia, las escuelas cuentan con docentes que trabajan con los alumnos que presentan mayores rezagos en las distintas asignaturas, entregando reforzamiento personalizado durante la jornada escolar. En Chile se podría utilizar a los estudiantes que están en el último año de su carrera de pedagogía para trabajar junto con los docentes de aulas, prestando apoyo personalizado a los escolares que presentan el mayor riesgo de desertar.
} 
b. Flexibilizar el pago de la subvención omitiendo la asistencia o estableciendo un piso mínimo entre $85 \%$ y $90 \%$, y así dejar un espacio reducido de incentivo a las escuelas para que promuevan la asistencia.

\section{CONCLUSIONES}

El presente artículo muestra las desiguales condiciones de vida de las familias en Chile, mostrando los riesgos que conlleva la suspensión prolongada de las clases escolares presenciales en el contexto de confinamiento. Los factores que más inciden en la educación a distancia son las habilidades críticas para el aprendizaje a distancia (comprensión lectora y habilidades TIC), condiciones materiales para la educación remota (calidad de la vivienda y acceso a internet y a computador o Tablet) y el apoyo familiar al interior del hogar.

En estas tres dimensiones, los escolares chilenos presentan enormes carencias. Los resultados de la prueba SIMCE de Lectura (2018) muestran que casi un tercio de los estudiantes de cuarto básico y la mitad de los de segundo medio tienen un nivel de comprensión lectora insuficiente, que perjudica severamente el trabajo autónomo que exige el aprendizaje a distancia. Asimismo, los resultados de la prueba ICILS 2018 muestran que el 90\% de los escolares de octavo básico no cuenta con las habilidades TIC suficientes para usar de forma independiente un computador como herramienta para recopilar y manejar información. En relación con la segunda dimensión, el 15\% de los escolares vive en condiciones de hacinamiento. Considerando la calidad de la vivienda y el hacinamiento, uno de cada cuatro escolares vive en una vivienda con carencias. Respecto del acceso a un computador o a internet, el 29\% de los escolares no tiene acceso a un computador al interior de la vivienda y el $13 \%$ no tiene ningún tipo de acceso a internet. Si cruzamos los datos de calidad de la vivienda con el acceso a computador e internet, advertimos que el $47 \%$ de los estudiantes no cuenta con las condiciones mínimas para el aprendizaje a distancia. Respecto de la última dimensión, el 40\% de los escolares vive en hogares cuyo jefe de hogar no cuenta con Enseñanza Media completa y el 16\% no cuenta con al menos un adulto con Enseñanza Media completa en su vivienda. Finalmente, el $30 \%$ de los escolares vive en una vivienda donde no hay nin- 
gún adulto durante la jornada escolar. Este porcentaje aumenta a $42 \%$ si consideramos como no disponibles a los adultos que estudian jornada completa en la educación superior, a quienes estudian y trabajan, y a quienes están buscando trabajo.

A nivel nacional, dos de cada tres escolares presentan carencias en las dos últimas dimensiones, perjudicando la factibilidad del aprendizaje a distancia. Pero más dramática aún es la desigual distribución de estas carencias en función del nivel socioeconómico de las familias. Mientras el $68 \%$ de los escolares del primer quintil de ingresos presenta carencias en la condición de su vivienda o no cuenta con acceso a un computador y a internet, solo el $10 \%$ de los escolares del quinto quintil de ingresos presenta alguna carencia en estas dimensiones. Una distribución similar se observa en las habilidades TIC y de comprensión de lectura, así como en el capital cultural del jefe de hogar.

Debido a las limitaciones de las bases de datos que usamos (CASEN, SIMCE, ICILS), no pudimos estimar el porcentaje de escolares que presenta carencias en las tres dimensiones analizadas. Sin embargo, en todas ellas los escolares de hogares más vulnerables son los que tienen las mayores carencias (con la excepción de la disponibilidad de un adulto durante la jornada escolar). Tampoco contamos con datos más recientes. Esto es particularmente relevante para la estimación de adultos con disponibilidad de tiempo, ya que depende de la situación ocupacional, la que presenta importantes variaciones producto de la crisis económica asociada a la pandemia. Sin embargo, creemos que tener esa información permite constatar patrones y diferencias que nutren las recomendaciones.

Diversas organizaciones internacionales y en general los especialistas médicos, han mostrado especial preocupación por los riesgos alimentarios y de salud mental en los niños a causa del cierre de las escuelas. A ello se suman los riesgos de pérdida de habilidades sociales, físicas y cognitivas, aumento de brechas en los aprendizajes al interior del aula, así como entre establecimientos, junto con el aumento de la deserción escolar. La crisis económica que hoy enfrentamos nos hará un país más pobre y desigual en el corto plazo, pero esta injusticia social puede verse prolongada si no encontramos la forma de retornar a las clases presenciales en el corto plazo, sin poner en riesgo la vida de las personas. $\mathrm{Si}$ 
consideramos los principales indicadores para predecir deserción escolar, advertimos que, antes de la pandemia, poco más de 50 mil alumnos presentaban ausentismo crónico junto con bajo rendimiento escolar. De este grupo, el $27 \%$ presentaba rezago escolar de al menos un año. Según la "La mirada de los docentes" (2020), la mitad de los alumnos no ha tenido contacto alguno con sus docentes, lo que podría llevar a un aumento importante de los estudiantes con riesgo de desertar.

Para mitigar los riesgos asociados a la suspensión de clases, destacamos la necesidad de volver lo antes posible a las clases presenciales. Para ello sugerimos una serie de recomendaciones inspiradas en la experiencia internacional y en las particularidades de nuestro sistema educativo que pueden ser de utilidad para un retorno seguro. Entre ellas destacamos los protocolos y medidas que apuntan a resguardar la salud de los escolares y sus familias; la necesidad de implementar una estrategia dinámica y flexible de retorno a clases, que permita abrir y cerrar los establecimientos en función de las circunstancias locales; avanzar decididamente en acortar las brechas de conectividad; capacitar y acompañar a los docentes, especialmente en lo que respecta a las habilidades TIC, herramientas para el apoyo emocional de los estudiantes e identificación de situaciones complejas, así como en didácticas de aprendizaje a distancia; y estrategias para el trabajo a distancia con niños y adolescentes que por circunstancias familiares no se incorporen inmediatamente a la escuela. Dado que el aprendizaje a distancia se mantendrá de forma intermitente por lo menos hasta el próximo año, también entregamos una serie de recomendaciones que buscan especialmente mitigar el rezago en los aprendizajes y la deserción escolar. Estas recomendaciones generales deben, a la hora de su implementación, adecuarse a los distintos tramos de edad de los niños, que por su nivel de desarrollo tienen exigencias distintas. Finalmente, es importante destacar que las recomendaciones acerca del pronto retorno a las clases presenciales presuponen un bajo riesgo de contagio y de presentar síntomas de COVID-19 para los niños. Sin embargo, todavía tenemos un escaso conocimiento del virus, de manera que estas recomendaciones deben ser revisadas permanentemente, considerando los nuevos antecedentes que entrega la información científica sobre el peligro del virus para niños y adolescentes. 


\section{BIBLIOGRAFÍA}

Agencia de Calidad de la Educación 2020a. Portal de Estudios. Disponible en: http://informacionestadistica.agenciaeducacion.cl/\#/bases [1 de julio 2020].

Agencia de Calidad de la Educación 2020b. Metodología de Construcción de Grupos Socioeconómicos. Pruebas SIMCE 2012. Disponible en: http:// archivos.agenciaeducacion.cl/Metodologia-de-Construccion-de-GruposSocioeconomicos-SIMCE-2012.pdf [1 de julio 2020].

Almond, D., Currie, J. y Duque, V. 2018. Childhood Circumstances and Adult Outcomes: Act II. Journal of Economic Literature, American Economic Association 56(4), 1360-1446.

Balfanz, R., Herzog, L. y Mac Ive, D. 2007. Preventing Student Disengagement and Keeping Students on the Graduation Path in Urban Middle-Grades Schools: Early Identification and Effective Interventions. Educational Psychologist 42, 223-235.

Banco Mundial 2018. Datos de libre acceso del Banco Mundial. Disponible en: https://datos.bancomundial.org [1 de julio 2020].

Beatty, A., Neisser, U., Trent, W. y Heubert, J. (eds.) 2001. Understanding Dropouts: Statistics, Strategies, and High-Stakes Testing. Washington: National Academy Press.

Benítez, A., Velasco, C. y Vergara, R. 2020. Coronavirus: antecedentes sanitarios y económicos para la discusión. Puntos de Referencia 532. Disponible en: https:// www.cepchile.cl/cep/puntos-de-referencia/puntos-de-referencia-2010-2020/ puntos-de-referencia-2020/coronavirus-antecedentes-sanitarios-y-economicospara-la-discusion [1 de julio 2020].

Bick, J. y Nelson, C. 2016. Early Adverse Experiences and the Developing Brain. Neuropsychopharmacology 41, 177-196.

Blondal, K. y Adalbjarnardottir, S. 2014. Parenting in Relation to School Dropout Through Student Engagement: A Longitudinal Study. Journal of Marriage and Family 76(4), 778-795.

Bonnery, S. 2003. Le décrochage scolaire de l'intérieur: interaction de processus sociaus, cognitifs, subjectifs et langagiers. Les Sciences de l'éducation 39(1), 39-58.

Bonomelli, F., Castillo A. y Croquevielle, J. 2020. Medición de la exclusión escolar en Chile. Documento de Trabajo 20. Centro de Estudios Mineduc. Ministerio de Educación, Chile. Disponible en: https://centroestudios.mineduc.cl/wpcontent/uploads/sites/100/2020/04/DOCUMENTO-DE-TRABAJO-20_2020_ f01.pdf [1 de julio 2020].

Bos, M., Minoja, L. y Dalaison, W. 2020. Strategies for School Reopenings during the COVID-19 Pandemic. IDB (InterAmerican Development Bank). Disponible en: https://publications.iadb.org/en/strategies-for-schoolreopenings-during-the-covid-19-pandemic [1 de julio 2020]. 
Brito, N. y Noble, K. 2014. Socioeconomic Status and Structural Brain Development. Frontiers in Neuroscience 8, 276. DOI: 10.3389/fnins.2014.00276.

Britto, P., Lye, S., Proulx, K. et al. 2017. Nurturing Care: Promoting Early Childhood Development. The Lancet 389 (10.064), 91-102.

Burns, T. y Gottschalk, F. (eds.) 2019. Trends in Children's Emotional Well-Being. Educating 21st Century Children: Emotional Well-Being in the Digital Age. Paris: OECD Publishing. DOI: https://doi.org/10.1787/3b7cb397-en.

CASEN 2017. Resultados Encuesta CASEN 2017. Disponible en: http://observatorio. ministeriodesarrollosocial.gob.cl/casen-multidimensional/casen/casen_2017.php [1 de julio 2020].

Centro de Estudios Mineduc 2018. Indicadores de la Educación en Chile 20102016. Ministerio de Educación, Chile. Disponible en: https://centroestudios. mineduc.cl/wp-content/uploads/sites/100/2018/03/INDICADORES_baja.pdf [3 de agosto 2020].

Centro de Estudios Mineduc 2020. Resultados encuesta online Consulta de Continuidad de Aprendizajes - Establecimientos. Informe.

Clair, A. 2019. Housing: An Under-Explored Influence on Children's Well-Being and Becoming. Child Indicators Research 12, 609-626. DOI: https://doi. org/10.1007/s12187-018-9550-7.

Claro, S., Paunesku, D. y Dweck, C.A. 2016. Growth Mindset Tempers the Effects of Poverty on Academic Achievement. Proceedings of the National Academy of Science 113(31), 8664-8668.

Cooper, H., Nye, B., Charlton, K., Lindsay, J. y Greathouse, S. 1996. The Effects of Summer Vacation on Achievement Test Scores: A Narrative and MetaAnalytic Review. Review of Educational Research 66(3), 227-268.

Corral-Verdugo, V., Barrón, M., Cuen, A. y Tapia-Fonllem, C. 2011. Housing Habitability, Stress and Family Violence. PsyEcology 2(1), 3-14. DOI: https:// doi.org/10.1174/217119711794394644.

Cortés-Rojas, L., Portales-Olivares, J. y Peters-Obregón, H. 2019. Desescolarización, exclusión educativa y el desafío del reingreso escolar en Chile. Revista Saberes Educativos 3, 143-151.

Davies, N.G., Klepac, P., Liu, Y., Prem, K., Jit, M., CMMID COVID-19 Working Group y Eggo, R.M. 2020. Age-Dependent Effects in the Transmission and Control of COVID-19 Epidemics. Nature Medicine. DOI: https://doi. org/10.1038/s41591-020-0962-9.

ELPI (Encuesta Longitudinal de la Primera Infancia) 2017. Centro UC Encuestas y Estudios Longitudinales. Disponible en: www.elpi.cl [1 de agosto 2020].

Espinoza, O., Castillo, D., González, L., Loyola, L. y Santa Cruz, J. 2014. Deserción escolar en Chile: un estudio de caso en relación con factores intraescolares. Educación y Educadores 17(1), 32-50.

European Commission 2013. Reducing Early School Leaving: Key Messages and Policy Support. European Commission. Disponible en: https://ec.europa.eu/ education/sites/education/files/early-school-leaving-group2013-report_en.pdf [1 de julio 2020]. 
Evans, G. 2006. Child Development and the Physical Environment. Annual Review of Psychology 57(1), 423-451. DOI: https://doi.org/10.1146/annurev. psych.57.102904.190057.

Ferguson, K., Cassells, R., MacAllister, J. y Evans, G. 2013. The Physical Environment and Child Development: An International Review. International Journal of Psychology 48(4), 437-468. DOI: https://doi.org/10.1080/00207594 .2013.804190.

Fraillon, J., Ainley, J., Schulz, W., Friedman, T. y Duckworth, D. 2020. Preparing for Life in a Digital World: IEA International Computer and Information Literacy Study 2018 International Report. Springer International Publishing. DOI: https://doi.org/10.1007/978-3-030-38781-5.

Franklin, B. y Trouard, S. 2014. An Analysis of Dropout Predictors within a State High School Graduation Panel. Schooling 5, 1-8.

Giannini, S., Jenkins, R. y Saavedra, J. 2020. Reopening Schools: When, Where and How? World Bank Blogs. Disponible en: https://blogs.worldbank.org/ education/reopening-schools-when-where-and-how [1 de julio 2020].

Gleason, P. y Dynarski, M. 2002. Do We Know Whom to Serve? Issues in Using Risk Factors to Identify Dropouts. Journal of Education for Students Placed at Risk 7(1), 25-41.

Hawryluck, L., Gold, W., Robinson, S., Pogorski, S., Galea, S. y Styra, R. 2004. SARS Control and Psychological Effects of Quarantine, Toronto, Canada. Emerging Infectious Diseases 10(7), 1206-1212. DOI: http://dx.doi. org/10.3201/eid1007.030703.

ICILS (Estudio Internacional de Alfabetización Computacional y Manejo de Información) 2018. ICILS. Disponible en: https://www.agenciaeducacion.cl/ estudios/estudios-internacionales/icils/ [1 de julio 2020].

IHME (Institute for Health Metrics and Evaluation) 2020. IHME Measuring What Matters. Disponible en: http://www.healthdata.org [1 de julio 2020].

INE (Instituto Nacional de Estadísticas) 2017. INE. Disponible en: https://www.ine. cl [1 de julio 2020].

INE (Instituto Nacional de Estadísticas) 2020. INE. Disponible en: https://www.ine. cl [1 de julio 2020].

Jiménez, G. 2007. El funcionamiento de la cárcel como exclusión en Chile. Santiago: División de Planificación, Estudios e Inversión del Departamento de Estudios, Ministerio de Planificación.

Jochim, A. 2020. Will States Step Up to Address Gaps in Access to Remote Learning This Fall? July 20. Center on Reinventing Public Education. Disponible en: https://www.crpe.org/thelens/will-states-step-address-gapsaccess-remote-learning-fall [29 de julio 2020].

Kuhfeld, M. y Soland, J. 2020. The Learning Curve: Revisiting the Assumption of Linear Growth across the School Year. EdWorkingPaper 20-214. Annenberg Institute at Brown University. DOI: https://doi.org/10.26300/bvg0-8g17.

La mirada de los docentes 2020. Docencia durante la crisis sanitaria: La mirada de los docentes. Disponible en: http://miradadocentes.cl [1 de julio 2020]. 
Lansford, J., Dodge, K., Pettit, G. y Bates, J. 2016. A Public Health Perspective on School Dropout and Adult Outcomes: A Prospective Study of Risk and Protective Factors From Age 5 to 27 Years. Journal of Adolescent Health 58(6), 652-658. DOI: https://doi.org/10.1016/j.jadohealth.2016.01.014.

Latif, A., Choudhary, A. y Hammayun, A. 2014. Economic Effects of Student Dropout: A Comparative Study. Journal of Global Economics 3, 137. DOI:10.4172/2375-4389.1000137.

Lawson, G., Camins, J., Wisse, L., Wu, J., Duda, J., Cook, P., Gee, C. y Farah, M. 2017. Childhood Socioeconomic Status and Childhood Maltreatment: Distinct Associations with Brain Structure. PLoS One 12, e175690. DOI: https://doi. org/10.1371/journal.pone.0175690.

Lee, B. y Raszka, W. 2020. COVID-19 Transmission and Children: The Child is Not to Blame. Pediatrics 146(2), e2020004879. DOI: https://doi.org/10.1542/ peds.2020-004879.

Marcano, J. 2020. Se disparan en cuarentena las llamadas de emergencia por violencia contra la mujer. El Mercurio, 26 de julio, A12. Disponible en: https://merreader.emol.cl/2020/07/26/A/LK3QUEIK/light?gt=001201 [1 de julio 2020].

Marchbanks, M., Blake, J., Booth, E., Carmichael, D., Seibert, A. y Fabelo, T. 2015. The Economic Effect of Exclusionary Discipline on Grade Retention and High School Dropout (59-74). En Losen, D. (ed.), Closing the School Discipline Gap. New York: Teachers College Press.

Martínez, F. 2015. El rol de las expectativas docentes en los procesos de enseñanzaaprendizaje de la matemática. Tesis de Magíster en Economía Aplicada, Universidad de Chile.

MDSF (Ministerio de Desarrollo Social y Familia) 2018. CASEN 2017. Manual del investigador. Disponible en: http://observatorio.ministeriodesarrollosocial. gob.cl/casen-multidimensional/casen/docs/Manual_del_Investigador_ Casen_2017.pdf [1 de julio 2020].

Mefalopulos, P. 2020. Coronavirus y violencia hacia la infancia. Declaración Representante de UNICEF en Chile. UNICEF, 27 de abril. Disponible en: https://www.unicef.org/chile/historias/coronavirus-y-violencia-hacia-lainfancia [26 de julio 2020].

Mineduc (Ministerio de Educación) 2019. Datos abiertos. Ministerio de Educación, Chile. Disponible en: http://datosabiertos.mineduc.cl [1 de julio 2020].

Monckeberg, F. (ed.) 1988. Desnutrición infantil. Fisiopatología clínica, tratamiento y prevención: nuestra experiencia y contribución. Santiago: Instituto de Nutrición y Tecnología de los Alimentos, Universidad de Chile, Impresora Creces.

Monckeberg, F., Valiente, S. 1976. Antecedentes y acciones para una política nacional de alimentación y nutrición de Chile. Santiago: Gabriela Mistral.

Morales, P. 2020. Niños vulnerables sin ir al colegio: cuando pierden su único espacio seguro. La Tercera, 20 de abril. Disponible en: https://www.latercera. com/paula/ninos-en-riesgo-social-violencia-cuarentena-sin-clases-chilepoblacion-vulnerable-defensora-de-la-ninez-chile/ [26 de julio 2020]. 
Morgan, K., Melendez-Torres, G., Bond, A., Hawkins, J., Hewitt, G., Murphy, S. y Moore, G. 2019. Socio-Economic Inequalities in Adolescent Summer Holiday Experiences, and Mental Wellbeing on Return to School: Analysis of the School Health Research Network/Health Behaviour in School-Aged Children Survey in Wales. International Journal of Environmental Research and Public Health 16(7), 1107. DOI: 10.3390/ijerph16071107.

Neild, R. y Balfanz, R. 2006. The Dimensions and Characteristics of Philadelphia's Dropout Crisis, 2000-2005. Baltimore: Center for Social Organization of Schools, Johns Hopkins University.

Nord, M. y Romig, K. 2006. Seasonal Food Insecurity and the National School Lunch and Summer Food Service Programs. Journal of Children and Poverty 12(2), 141-158. DOI: 10.1080/10796120600879582.

Nussbaumer-Streit, B., Mayr, V., Dobrescu, A., Chapman, A., Persad, E., Klerings, I., Wagner, G., Siebert, U., Christof, C., Zachariah, C. y Gartlehner, G. 2020. Quarantine Alone or in Combination with other Public Health Measures to Control COVID-19: A Rapid Review. Cochrane Database of Systematic Reviews 4(4), CD013574. DOI: 10.1002/14651858.CD013574.

O’Dwyer, L., Russell, M., Bebell, D. y Tucker-Seeley, K. 2005. Examining the Relationship between Home and School Computer Use and Students' English/Language Arts Test Scores. The Journal of Technology, Learning and Assessment 3(3). Disponible en: https://files.eric.ed.gov/fulltext/EJ848513.pdf [1 de julio 2020].

OCDE 2016. Socio-Economic Status, Student Performance and Students' Attitudes towards Science. En OECD, PISA 2015 Results. Vol. I. Excellence and Equity in Education. Paris: PISA, OECD Publishing. DOI: http://dx.doi. org/10.1787/9789264266490-en.

OCDE 2020a. Combatting COVID-19's Effect on Children. Disponible en: http:// www.oecd.org/coronavirus/policy-responses/combatting-covid-19-s-effect-onchildren-2e1f3b2f/ [1 de julio 2020].

OCDE 2020b. Coronavirus Special Edition: Back to School. Disponible en: https:// www.oecd-ilibrary.org/docserver/339780fd-en.pdf?expires $=1595711856 \& \mathrm{id}=$ id\&accname $=$ guest $\&$ checksum=FFF380B2D5852A909E3DDA7382F56EFD [1 de julio 2020].

OCDE 2020c. Education Responses to COVID-19: Embracing Digital Learning and Collaboration. Disponible en: http://www.oecd.org/coronavirus/policyresponses/education-responses-to-covid-19-embracing-digital-learning-andonline-collaboration-d75eb0e8/ [1 de julio 2020].

Park, Y., Choe, Y., Park, O., Park, S., Kim, Y. et al. 2020. Contact Tracing during Coronavirus Disease Outbreak, South Korea, 2020. Emerging Infectious Diseases Journal. DOI: https://doi.org/10.3201/eid2610.201315.

Peña, J.C., Soto, V. y Calderón, U. 2016. La influencia de la familia en la deserción escolar. Revista Mexicana de Investigación Educativa 21(70), 881-899.

Public Health Agency of Sweden 2020. COVID-19 in Schoolchildren. A Comparison Between Finland and Sweden. Disponible en: https://www. 
folkhalsomyndigheten.se/contentassets/c1b78bffbfde4a7899eb0d8ffdb57b09/ covid-19-school-aged-children.pdf [1 de julio 2020].

Quinn, D. y Polikoff, M. 2017. Summer Learning Loss: What Is It, and What Can We Do about It. Brookings Institution. Disponible en: https://www.brookings. edu/research/summer-learning-loss-what-is-it-and-what-can-we-do-about-it/ [1 de julio 2020].

Raczynski, D. 2002. Procesos de Deserción en la Enseñanza Media. Factores Expulsores y Protectores. Santiago, Instituto Nacional de la Juventud (Injuv).

Ramírez, M. 2007. Diferencias dentro de las salas de clases. Distribución del rendimiento en matemáticas. Estudios Públicos 106, 5-22. Disponible en: https://www.cepchile.cl/diferencias-dentro-de-las-salas-de-clases-distribuciondel-rendimiento/cep/2016-03-04/094219.html [1 de julio 2020].

Reimers, F. y Schleicher, A. 2020. Schooling Disrupted, Schooling Rethought. How the COVID-19 Pandemic is Changing Education. Paris: OCDE Publishing. Disponible en: https://globaled.gse.harvard.edu/files/geii/files/education continuity_v3.pdf [1 de julio 2020].

Rice, K. 2006. A Comprehensive Look at Distance Education in the K-12 Context. Journal of Research on Technology in Education 38(4), 425-448. DOI: https:// doi.org/10.1080/15391523.2006.10782468.

Rivas, F., Beltrán, J. y Salazar, O. 2013. Factores gatilladores de la deserción escolar presentes en las representaciones sociales que subyacen en el discurso de los docentes. Revista Investigaciones en Educación XIII(2), 113-134.

Roblyer, M.D., Davis, L., Mills, S.C., Marshall, J. y Pape, L. 2008. Toward Practical Procedures for Predicting and Promoting Success in Virtual School Students. American Journal of Distance Education 22(2), 90-109. DOI: https://doi.org/10.1080/08923640802039040.

Roschelle, J., Rafanan, K., Bhanot, R., Estrella, G., Penuel, W., Nussbaum, M. y Claro, S. 2010. Scaffolding Group Explanation and Feedback with Handheld Technology: Impact on Students' Mathematics Learning. Educational Technology Research and Development 58, 399-419.

Russell, V., Russell, S., Croker, H., Packer, J., Ward, J., Stansfield, C. et al. 2020. School Closure and Management Practices during Coronavirus Outbreaks Including COVID-19: A Rapid Systematic Review. The Lancet. Child \& Adolescent Health 4, 397-404. DOI: https://doi.org/10.1016/S23524642(20)30095-X.

Santos, H. 2008. Dinámica de la deserción escolar en Chile. Santigo: Departamento de Estudios, División Social, Mideplan.

Shonkoff, J., Boyce, W. y McEwen, B. 2009. Neuroscience, Molecular Biology, and the Childhood Roots of Health Disparities: Building a New Framework for Health Promotion and Disease Prevention. Journal of the American Medical Association 301(21), 2252-2259.

SIMCE 2017. Portal de Estudios. Disponible en: http://informacionestadistica. agenciaeducacion.cl/\#/bases [1 de julio 2020]. 
SIMCE 2018. Portal de Estudios. Disponible en: http://informacionestadistica. agenciaeducacion.cl/\#/bases [1 de julio 2020].

Smerillo, N.E., Reynolds, A.J., Temple, J.A. y Ou, S.-R. 2018. Chronic Absence, Eighth-Grade Achievement, and High School Attainment in the Chicago Longitudinal Study. Journal School Psychology 67, 163-178.

Sprang, G. y Siman, M. 2013. Posttraumatic Stress Disorder in Parents and Youth After Health-Related Disasters. Disasters Medicine and Public Health Preparedness 7(1), 105-110.

Subsecretaría de Prevención del Delito 2017. Tercera Encuesta Nacional de Violencia Intrafamiliar Contra la Mujer y Delitos Sexuales. Ministerio del Interior y Seguridad Pública. Disponible en: http://cead.spd.gov.cl/estudios-yencuestas/ [1 de julio 2020].

Symeou, L. 2006. Capital cultural y social: ¿qué podemos aprender para investigar y reforzar la colaboración entre familia y escuela? Cultura y Educación 18(34), 219-229. DOI: https://doi.org/10.1174/113564006779173037.

The Economist 2020. The Pandemic Is Widening Educational Inequality. The Economist, 27 de julio. Disponible en: https://www.economist.com/graphicdetail/2020/07/27/the-pandemic-is-widening-educational-inequality [29 de julio 2020].

Torjesen, I. 2020. COVID-19: Researchers Question Policy of Closing Schools after Finding under 20s Have Low Susceptibility to Virus. BMJ 369:m2439. DOI: https://doi.org/10.1136/bmj.m2439.

UNESCO 2020a. Crisis y currículo durante el COVID-19: Mantención de los resultados de calidad en el contexto del aprendizaje remoto. Nota Temática 4.2. Disponible en: https://unesdoc.unesco.org/ark:/48223/pf0000373273_spa [1 de julio 2020].

UNESCO 2020b. Mitigating the Effects of the COVID-19 Pandemic on Food and Nutrition of Schoolchildren. Disponible en: https://www.unicef.org/sites/ default/files/2020-04/Mitigating-the-Effects-of-the-COVID-19-Pandemic-onFood-and-Nutrition-of-school-children.pdf [1 de julio 2020].

Unidad de Currículum y Evaluación 2013. Estándares de Aprendizaje Lectura Cuarto Básico. Ministerio de Educación, Chile. Disponible en: https:// curriculumnacional.mineduc.cl/614/articles-34979_recurso_5.pdf [1 de julio 2020].

Unidad de Currículum y Evaluación 2015. Estándares de Aprendizaje Lectura Segundo Medio. Ministerio de Educación, Chile. Disponible en: https:// curriculumnacional.mineduc.cl/614/articles-34979_recurso_9.pdf [1 de julio 2020].

U.S. Department of Education 2016. Chronic Absenteeism in the Nation's Schools: A Hidden Educational Crisis. Disponible en: https://www2.ed.gov/datastory/ chronicabsenteeism.html [1 de julio 2020].

Vásquez, R., Ramos, M. y Maravilla, G. 2009. Consumo de droga(s) y aprovechamiento escolar; la convivencia y sus problemas; microculturas juveniles en la escuela. Memorias del X Congreso Nacional de Investigación 
Educativa, Veracruz. Disponible en: http://www.comie.org.mx/congreso/ memoriaelectronica/v10/pdf/area_tematica_17/ponencias/1372-F.pdf [1 de julio 2020].

Vaughn, M., Beaver, K., Wexler, J., De Lisi, M. y Roberts, G. 2011. The Effect of School Dropout on Verbal Ability in Adulthood: A Propensity Score Matching Approach. Journal of Youth Adolescence 40(2), 197-206. DOI: 10.1007/ s10964-009-9501-1.

Vergara, R. 2020. El momento económico internacional y nacional. Puntos de Referencia 539. Disponible en: https://www.cepchile.cl/cep/puntos-dereferencia/puntos-de-referencia-2010-2020/puntos-de-referencia-2020/elmomento-economico-internacional-y-nacional-junio-2020 [27 de julio 2020]. 


\section{APÉNDICE}

Tabla 1. DESCOMPOSICIÓN DE LA VARIANZA DE PUNTAJES SIMCE LECTURA 2018, SEGUNDO MEDIO

\begin{tabular}{|c|c|c|c|c|}
\hline Nivel & $\begin{array}{c}\text { Grados de } \\
\text { libertad }\end{array}$ & $\begin{array}{c}\text { Suma de cua- } \\
\text { drados }\end{array}$ & $\begin{array}{c}\text { Proporción de la } \\
\text { varianza entre } \\
\text { grupos }\end{array}$ & $\begin{array}{c}\text { Proporción de la } \\
\text { varianza ajustada } \\
\text { entre grupos }\end{array}$ \\
\hline Regiones & 15 & 396.224 & 0,001 & 0,001 \\
\hline Provincias & 55 & 1.902 .907 & 0,004 & 0,003 \\
\hline Comunas & 324 & 16.431 .308 & 0,037 & 0,033 \\
\hline Establecimientos & 2.834 & 102.200 .000 & 0,229 & 0,192 \\
\hline Cursos & 6.942 & 125.700 .000 & 0,282 & 0,053 \\
\hline Alumnos dentro de cursos & 184.240 & 446.200 .000 & - & 0,718 \\
\hline
\end{tabular}

Tabla 2. DESCOMPOSICIÓN DE LA VARIANZA DE PUNTAJES SIMCE LECTURA 2018, CUARTO BÁSICO

\begin{tabular}{|c|c|c|c|c|}
\hline Nivel & $\begin{array}{c}\text { Grados de } \\
\text { libertad }\end{array}$ & $\begin{array}{l}\text { Suma de } \\
\text { cuadrados }\end{array}$ & $\begin{array}{c}\text { Proporción de la } \\
\text { varianza entre } \\
\text { grupos }\end{array}$ & $\begin{array}{c}\text { Proporción de la } \\
\text { varianza ajustada } \\
\text { entre grupos }\end{array}$ \\
\hline Regiones & 15 & 1.299 .755 & 0,002 & 0,002 \\
\hline Provincias & 55 & 3.169 .223 & 0,005 & 0,003 \\
\hline Comunas & 331 & 21.503 .615 & 0,036 & 0,030 \\
\hline Establecimientos & 5.086 & 113.000 .000 & 0,187 & 0,151 \\
\hline Cursos & 7.921 & 125.700 .000 & 0,208 & 0,021 \\
\hline Alumnos dentro de cursos & 213.474 & 604.489 .259 & - & 0,792 \\
\hline
\end{tabular}

